\title{
Asymmetric Networks in Two-Sided Markets ${ }^{7}$
}

\author{
By Attila Ambrus and Rossella Argenziand*
}

\begin{abstract}
This paper investigates pricing decisions and network choices in twosided markets with network externalities. Consumers are heterogeneous in how much they value the externality. Imposing restrictions on the extent of coordination failure among consumers generates clear qualitative conclusions about equilibrium market configurations. Multiple asymmetric networks can coexist in equilibrium, both in the case of a monopolist network provider and in the case of competing providers. These equilibria have the property that one network is cheaper and larger on one side, while the other network is cheaper and larger on the other side. Product differentiation is endogenized by consumers' network choices. (JEL D85, L12, L13, L14, D42, D43)
\end{abstract}

\begin{abstract}
market has network externalities if a consumer's utility from purchasing a product depends on which other consumers buy the same product. A highlighted special case of this is two-sided markets with network externalities. In these markets, consumers are divided into two distinct subgroups. A consumer's utility on one side increases in the total number of consumers on the other side of the market who buy the same product (and possibly decreases in the number of consumers on the same side of the market). This applies to various situations in which two groups of agents need a common platform to interact and one or more firms own platforms and sell access to them. The higher the number of agents on one side who join a platform, the higher the utility of an agent on the other side of the platform, because that agent has a higher number of potential partners with whom to trade or interact. Examples of these types of networks include payment card systems, where the two sides are cardholders and merchants; videogame platforms, where the two sides are game developers and final users; managed care plans, where the two sides are health providers and patients; classified advertising; and directory services.
\end{abstract}

\footnotetext{
* Ambrus: Department of Economics, Harvard University, 1805 Cambridge Street, Cambridge, MA 02138 (e-mail: ambrus@fas.harvard.edu); Argenziano: Department of Economics, University of Essex, Wivenhoe Park, Colchester, CO4 3SQ, UK (e-mail: rargenz@essex.ac.uk). Previous versions of this paper were circulated under the title "Network Markets and Consumer Coordination." We would like to thank Dirk Bergemann, Bernard Caillaud, Gergely Csorba, Ulrich Doraszelski, Erica Field, Drew Fudenberg, Dino Gerardi, Bruno Jullien, Stephen Morris, Gábor Virág, and seminar participants at Yale University, Harvard University, Olin School of Business, at the Conference on Two-Sided Markets organized by IDEI Toulouse, and at the 31st TPRC for comments and suggestions.

${ }^{\dagger}$ To comment on this article in the online discussion forum visit the articles page at: http://www.aeaweb.org/articles.php?doi=10.1257/mic.1.1.17
} 
Because of positive network externalities, the utility of every consumer is maximized if all of them join the same platform. Despite this, multiple large networks coexist in many of these markets. This observation holds both for markets in which there is a monopolist network provider (the same owner operates multiple networks) and for markets in which there are multiple competing providers. Furthermore, different networks in the same market are often priced quite differently. One type of market structure seems to be particularly common in two-sided markets. It involves two networks: one being cheaper and larger on one side of the market and the other being cheaper and larger on the other side. This configuration typically implies that most of the profit from operating a network comes from one side of the market, and that the two networks target different market sides. The cheap side of a network, which can even be subsidized and therefore generate loss, is used to create a large enough consumer base that makes it attractive for consumers on the other side of the market to join the network 1 ]

This paper investigates the conditions for multiple asymmetric networks coexisting in a two-sided market with network externalities. Our primary interests are to understand the decisions of firms regarding how many networks to operate and how to price them, and to investigate the resulting market shares on different sides of the market. We address these questions using an extensive form game. In the first stage, firms establish networks. In the second stage, they announce registration fees for these networks. In the third stage, consumers simultaneously choose networks or decide to stay out of the market. We investigate both the case of a monopolist network provider and the case of competing network providers. A central feature of our model is that we allow for heterogeneity among consumers with respect to how much they care about the externality (how much they value if there are a lot of consumers from the other side of the market on the same platform). This opens up a set of questions that have not been addressed in the existing literature: whether in equilibrium it is possible that different networks attract different types of consumers, and whether price discrimination among different types of consumers is possible in the absence of physical product differentiation.

As in all models with positive network externalities, there is a severe multiplicity of subgame perfect Nash equilibria in our game. To select among them, we use the concept of coalitional rationalizability proposed by Ambrus (2006). This solution concept allows groups of players to coordinate on playing certain strategies if it is in their mutual interest. The formal solution concept we use is subgame perfect Nash equilibria in which players play coalitionally rationalizable strategies in every subgame. The concept implies that after certain price announcements consumers can successfully coordinate on joining a particular network. For example, if there are two networks and one of them is cheaper on both sides of the market, then all consumers for whom it is not an iteratively dominated strategy to join some network end up joining the cheaper network. However, in other cases, when there is no focal network on which to coordinate, the concept does not necessarily impose successful coordination. In particular, the concept we use is strictly weaker in our setting than

\footnotetext{
${ }^{1}$ See Section II for several examples of this type of network structure in different settings.
} 
extensive form coalition-proof Nash equilibrium (B. Douglas Bernheim, Bezalel Peleg, and Michael D. Whinston 1987). ${ }^{2}$ This is in accordance with what we believe is a reasonable assumption for a market in which there is a large number of participants. In some cases, where there is a focal choice, coordination is successful, while in other cases it might not be. The concept we use is not related to requiring Pareto efficiency in subgames after price announcements. In particular, if consumers are heterogeneous, then Pareto efficiency can be a very weak requirement in the games we analyze. This is our main motivation for using a solution concept that considers coordination by subgroups of players (coalitions). Even if the set of all consumers cannot successfully coordinate on choosing a network, there might be focal choices for certain subgroups, establishing successful coordination within these groups.

We investigate the possibility of multiple asymmetric networks in coalition perfect equilibrium, and show that remarkably similar results hold for the case of a monopolist network provider as to the case of competing providers. For a monopolist provider, we show that if consumers are homogeneous in the sense of having the same reservation value for the network good (an assumption imposed in most of the related literature), then only one network is established in equilibrium. The reason is that dividing consumers into multiple networks would entail losing some gross consumer surplus, which would decrease the monopolist's profit. In case of competing providers, homogeneous consumers imply that either there is only one active network in equilibrium (all consumers join the same network), or there are two perfectly symmetric networks. In either case, both firms' profits are zero, just like in classic Bertrand competition without externalities. This holds despite the fact that equilibrium prices do not have to be equal to the marginal cost. Consumers on one side of the market can be subsidized while the other side might face a price above marginal cost.

The above results can be extended to cases when there is not too much heterogeneity among consumers (the ratio of reservation values between any two consumers is smaller than a certain threshold). However, we show that multiple asymmetric networks can coexist in coalition perfect equilibrium if there is enough heterogeneity among consumers.

A monopolist provider might want to establish two networks, which in equilibrium are joined by different types of consumers. The intuition is that, if there are consumers with high reservation values on both sides of the market, then the monopolist wants to extract surplus from both of these groups. However, if there are relatively few of these consumers and the monopolist operates only one network, then he can charge a high price on at most one side. In order to charge a high price, there must be enough consumers on the other side of the network, which is only possible if the price charged on the other side is low. However, if the monopolist establishes two networks such that one of them is cheap on one side of the market and the other network is cheap on the other side, then all consumers are willing to join some network, and consumers with high reservation values are willing to join the network that is more expensive for them. The way price discrimination is achieved in these

\footnotetext{
${ }^{2}$ Despite this, the qualitative conclusions of the model would be unchanged if we used coalition-proof Nash equilibrium as the solution concept. See the discussion on this in Section III.
} 
equilibria is through endogenous product differentiation. Networks are physically the same, but if one side of a network attracts many consumers, then the other side of the network becomes more valuable.

The same type of asymmetric equilibrium, in which different networks attract different types of consumers, can arise if there are competing network providers in the market. Moreover, in these equilibria, firms can get positive profits in Bertrand competition. The intuition is that although firms can steal each other's consumers by undercutting their rival's prices on both sides of the market, this strategy is not necessarily profitable. In particular, undercutting might increase the number of consumers to be subsidized more than the number of consumers who pay a positive price.

We show that in both the monopoly and duopoly cases, and for any distribution of consumer utility functions, all asymmetric equilibria with multiple active networks have the same qualitative features as the examples we provide. Namely, one network is cheaper and larger on one side of the market, and the other is larger and cheaper on the other side.

\section{Related Literature}

Recently, a number of papers investigated the issue of optimal pricing and price competition in markets with two-sided network externalities. For a more extensive literature review see, for example, Mark Armstrong (2006).

Marie-Odile Yanelle (1997) investigates competition in financial intermediation. She shows that Bertrand competition need not lead to zero profits, as is the case in our model. The reason why this can happen is quite different in our model than in Yanelle's model, however. In the latter, it is crucial that the intermediaries compete sequentially for the two sides of the market. This makes undercutting a competitor's price not necessarily an effective strategy. In our setup, network providers compete simultaneously for consumers on the two sides of the market, and undercutting is always effective (it "steals" all the consumers from the other network) but, as we show, not necessarily profitable.

Jean-Charles Rochet and Jean Tirole (2003) and Armstrong (2006) study monopolistic pricing and price competition between two firms on markets where the firms are platforms that try to attract two groups of agents. The models in these papers abstract away from coordination problems among consumers. They assume differentiable demand functions for the networks, implicitly assuming differentiated networks (i.e., assuming that consumers have heterogeneous inherent preferences between networks). Also, they focus on a particular symmetric equilibrium. Moreover, Rochet and Tirole emphasize the case in which the networks' primary pricing instruments are transaction fees.

Bruno Jullien (2001) constructs a duopoly model that allows for more than two subgroups of consumers and for both inter-group and intra-group network externalities. The context of this paper differs from ours mainly in that the intrinsic value of the good sold by each firm is assumed to be high compared to the network effect.

Glenn Ellison, Drew Fudenberg, and Markus Mobius (2004) study competition between two auction sites. In their model, as in ours, multiple asymmetric platforms can coexist in equilibrium despite the lack of product differentiation. In addition to 
this, they assume heterogeneous agents on both sides of the market. On the other hand, consumers choose platforms ex ante in their model, while in our paper, consumers do so after learning about their types. Furthermore, the reason that multiple active networks can coexist in equilibrium is completely different in their model. They consider a finite number of buyers and sellers. Thus, when one of them switches from one platform to another, he adversely affects the market price on the latter platform .3 In our model, there is a continuum of consumers on both sides of the market; therefore, this market-impact effect is absent.

The model in Ettore Damiano and Hao Li (2007, forthcoming) is similar to ours in that consumers in a two-sided market are heterogeneous, and that registration fees serve the role of separating different types of consumers. The main difference between our setup and theirs is that there is no network externality in theirs. Consumers care about the average quality, not the number, of consumers on the other side of the network. Whereas in our model, consumers are symmetric with respect to the external effect they generate on consumers on the other side.

The model closest to ours is presented by Bernard Caillaud and Jullien (2001, 2003). They analyze markets where firms are intermediaries offering matchmaking services to two groups of agents. The above papers assume that consumers on each side are homogeneous, and that their utilities are linear in the number of consumers on the other side of the network ${ }^{4}$ The assumption of homogeneity implies that these papers do not address most of the issues we investigate in this paper. Also, Caillaud and Jullien select among equilibria by imposing monotonicity of the demand function of consumers and by assuming full market coverage in equilibrium. Instead of making an assumption about the aggregate demand function, our paper imposes restrictions directly on the expectations of individual players.

In our model, different types of consumers might elect to join different networks. In this aspect, our analysis is connected to the literature on price discrimination (for an overview see Hal R. Varian 1989), multi-product pricing (see William J. Baumol, John C. Panzar, and Robert D. Willig 1982), and the theory of screening (for an overview see Bernard Salanie 1997).

\section{Motivating Examples: Asymmetric Networks in Various Two-Sided Markets}

The existence of multiple networks with different pricing strategies is a common phenomenon in two-sided markets. One network structure that appears in a wide variety of markets involves two networks: one that is larger and cheaper on one side of the market, and one that is larger and cheaper on the other side. This section provides examples in different settings.

The two main platforms in the market for online job search in the United States are Careerbuilder.com and Monster.com. The companies operating these Web sites act as intermediaries between employers and job seekers. Monster.com has a database of 56 million resumes versus Careerbuilder's 13 million. Therefore,

\footnotetext{
${ }^{3}$ See Glen Ellison and Drew Fudenberg (2003) for a detailed analysis of this point.

${ }^{4}$ For a comparison between our results in this context and the ones of Caillaud and Jullien (2003), see Subsection VA.
} 
Monster.com is larger on the job seekers' side. On the other hand, in February 2004, Careerbuilder had 45.2 percent of online job postings in the United States, while Monster had only 37.5 percent .5 Therefore, Careerbuilder is larger on this side. To buy two-week access to Careerbuilder's national database, a firm pays $\$ 500$, while two-week access to Monster's national database costs $\$ 9506$

Another example comes from the early history of the payment card industry. A payment card constitutes a platform that allows cardholders and merchants to complete their transactions. The first card to be introduced was the Diners Club charge card in 1949-1950, and it made most of its revenues on the merchants side. A few years later, American Express introduced its own payment card and chose the opposite pricing strategy. Quoting from David S. Evans and Richard Schmalensee (2005): "American Express adopted a slightly different pricing policy than Diners Club. It initially set its annual fee at $\$ 31, \$ 5$ higher than Diners Club, thereby suggesting that it was the more "exclusive" card. But it set the initial merchant discount slightly lower: 5 to 7 percent for restaurants; and 3 to 5 percent for the recalcitrant hotel industry, $[7$

In the US health insurance market, the vast majority of the population is enrolled in some form of managed care plan, which acts as a platform connecting health care providers and patients. A very common type of managed care plan is the Preferred Provider Organization (PPO). Sherman Folland, Allen Goodman, and Miron Stano (2004) describe them as follows: "PPO's give subscribers two distinct tiers of coverage. When subscribers use the PPO's preferred provider network, the required cost sharing is lower than when they use nonnetwork providers....Patients simply must pay more out of pocket if they choose to go outside the network...PPO contracts with physicians and hospitals generally address the prices providers will charge the PPO. In return for promising to charge a lower than average price, selected providers become part of the PPO's preferred network. No guarantee is given that the provider will see patients under the plan, but if the network is not too large and the PPO's cost-sharing provisions for subscribers are network-favorable, then the provider may enjoy a large increase in patient care business by joining the network." ${ }^{\prime 8}$ To summarize, a PPO typically operates two networks. One has a smaller set of providers and a large number of patients. This network is cheap for the patients, while providers are compensated less by the PPO for their services. The other network has many providers and a smaller number of patients. This network is expensive for patients, but providers get higher compensation for their services.

In the videogame market, the major competing platforms are PCs and a number of game consoles. The two sides of this market are players and game developers. For players, buying any of the game consoles currently on the market is significantly

\footnotetext{
52004 February figures. The information about the size of the two databases was obtained from the customer service departments of Careerbuilder and Monster. The prices for database access are available on each Web site. The information about the number of job postings was obtained from Corzen.

${ }^{6}$ The base cost of posting a résumé is zero on both sites, but job seekers pay extra fees for preferential treatment of their résumés (e.g., if they want them to come up at the top of search result lists obtained by firms). We do not have information on how many job seekers pay these extra fees. Therefore, we cannot make a correct price comparison on this side of the market.

${ }^{7}$ Evans and Schmalensee $(2005,59)$.

${ }^{8}$ Folland, Goodman, and Stano $(2004,256)$.
} 
cheaper than buying a PC configuration on which most games are enjoyable.$^{9}$ Game developers face the opposite price pattern. Publishing a game for a console requires paying royalties to the producer of the console, while publishing on PC is virtually free 10 Accordingly, most of the profit of console producers comes from royalties paid by game developers (typically the sales price of the console machines are subsidized, so by itself it generates a loss). As a result of the above pricing policies, the number of games that are available for a PC is very high, given that large game developers tend to multi-home on all platforms, while small, independent developers publish only on PC 11 At the same time, the estimated number of players using one of the popular game consoles considerably exceeds the number of players using a PC, judging by end-of-the-year sales statistics comparing different platforms 12

Finally, the type of network differentiation above is common in the market for classified ads as well. In many towns, there is a classified ad magazine that can be bought at newspaper stands, and there is also a freely distributed one. For advertisers, it is typically more expensive to place an ad in the freely distributed magazine, since it reaches a wider audience. For a concrete example, we acquired data from this market in Naples, Italy. The most popular classified ads magazine, "Bric-a-brac" (B.a.B.) (the third most sold journal in the region after the two main newspapers) costs $1,70 €$ and sells 13,000 copies every week. Its publisher, Inthesa FA s.r.l., also publishes a free press publication: "Free magazine motori (F.M.M.)," which has a circulation of 75,000 copies ${ }^{13}$ Both contain paid and free ads. A paid ad on F.M.M. costs about twice as much as the same ad on B.a.B. 14

\section{The Model}

We consider a standard model of price competition in two-sided markets with network externalities. It is a sequential move game in which first firms announce prices, then consumers observe the announcements, and finally consumers choose which network to join, if any. We examine the cases of one or two firms operating in the market. The new features of our model are the following. First, consumers are not assumed to be homogeneous in how much they value the network good. Second, we do not make any restriction on the utility functions of consumers besides quasi-linearity in money. Third, in the monopoly case, we allow the firm to choose the number of networks to be established.

\footnotetext{
${ }^{9}$ Among the standard requirements are: a fast processor, ample RAM, and a high-end video card.

${ }^{10}$ See David S. Evans, Andrei Hagiu, and Richard Schmalensee (2005) and "PC Gaming is NOT Dead, People," http://www.gamespot.com/features/burningquestions/?story=6122826.

${ }^{11}$ See for example "The State of Church: Doug Church on the Death of PC Gaming and the Future of Defining Gameplay," http://www.gamasutra.com/features/20041123/hall_01.shtml and "Interview: Ritual's Robert Atkins on Console Life, PC Death,” http://www.gamasutra.com/features/20050630/wen_01.shtml.

${ }^{12}$ See "The NPD Group reports annual 2004 US video game industry retail sales," http://www.npdfunworld.com/funServlet?nextpage=pr_body.html\&content_id=2076 and "The NPD Group reports on retail sales of US video game industry for first half 2005," http://www.npdfunworld.com/funServlet?nextpage=pr_body. html\&content_id=2173.

${ }^{13}$ Source: Inthesa FA s.r.1.

${ }^{14}$ F.M.M. is in color, while B.a.B. is black and white, but the normal surcharge for color on this market is 20 percent to 30 percent, so at least 70 percent of the surcharge is due to the larger circulation.
} 
Formally, the set of players in the model are two different sets of consumers (corresponding to the two sides of the market) and one or two platform providers. We assume there is a continuum of consumers on both sides of the market indexed by the interval $[0,1]$.

We consider a three-stage game with observable actions (i.e., after every stage, all players observe all action choices made in that stage).

In the first stage, the firms simultaneously choose how many networks to establish. We will restrict attention to cases in which the maximum number of networks a firm can operate is either one (in which case the decision at this stage is trivial) or two.

In the second stage, the firms simultaneously set prices (registration fees) for the established networks. Firms can charge different registration fees on different networks or on different sides of the same network. Furthermore, they can charge negative prices on either side of the networks (subsidizing consumers on that side) ${ }^{15}$ Let $p_{k}^{j}$ denote the price of network $k$ on side $j$. If there is only one network established, then we drop the subscript from the notation.

In the third stage, the consumers simultaneously choose which network to join, if any. We assume that a consumer can join at most one network (exclusivity of networks) ${ }^{16}$ Let $N_{k}^{j}$ denote the total number of consumers on side $j$ who join network $k$.

Firms maximize profits. We assume that firms are identical and that the cost of operating a network is zero, independent of the number of consumers joining the network .17 Therefore, the payoff of the firm is the sum of the revenues collected from the firm's networks, where the revenue collected from a network is the sum of the revenue collected on side one and the revenue collected on side two. The profit accumulated at network $k$ is $\sum_{j=1}^{2} p_{k}^{j} N_{k}^{j}$.

Consumer $i$ on side $j$ maximizes the individual-specific utility function $U_{i}^{j}$. Let $U_{i}^{j}=0$ if she does not join any network. Let $U_{i}^{j}=g_{i}^{j}\left(N_{k}^{-j}\right)-p_{k}^{j}$ if she joins network $k$. Assume $g_{i}^{j}(0)=0$, and that $g_{i}^{j}$ is strictly increasing for every consumer $C_{i}^{j}[18] \mathrm{A}$ consumer's utility when joining a network is quasilinear in money and increases in the number of people joining the network from the other side of the market. 19 Implicit in the construction is that consumers do not have any inherent preference for joining one network or another. They only care about the number of people joining the networks and the price they have to pay.

\footnotetext{
${ }^{15}$ It is quite common to observe that consumers on one side of a two-sided market get subsidized when they join a platform. Typically, the subsidy takes the form of free goods or free extra services. For example, clubs often offer women free entry and a free drink.

${ }^{16}$ See Section VIB for a discussion on relaxing this assumption.

${ }^{17}$ See Section VIA for a discussion on how the results are affected when assuming a positive marginal cost.

${ }^{18} \mathrm{We}$ assume that network participation is a pure network good for analytical convenience. Most results of the paper could be generalized to the case of $g_{i}^{j}(0) \geq 0$.

${ }^{19}$ The above specification makes the simplifying assumption that a consumer's utility is independent of how many consumers join the network on her side, implicitly assuming that interacting with consumers on the other side is a nonrival activity. Section VIC discusses implications of partially relaxing this assumption.
} 
For some of the forthcoming results, we will also assume that incremental utilities resulting from a given increase in the number of consumers on the other side are uniformly bounded by a positive constant:

A1: For every $0 \leq N<N^{\prime} \leq 1$ and every $j \in\{1,2\}$, there exists a constant $\delta^{j}\left(N, N^{\prime}\right)$ $>0$ such that $g_{i}^{j}\left(N^{\prime}\right)-g_{i}^{j}(N) \geq \delta\left(N, N^{\prime}\right) \forall i \in[0,1]$.

Let $u_{i}^{j}=g_{i}^{j}(1)$. We call $u_{i}^{j}$ the reservation value of consumer $i$ on side $j$.

If $g_{i}^{j}=g_{i^{\prime}}^{j} \forall i, i^{\prime} \in[0,1]$ and $j \in\{1,2\}$, then we say consumers are homogeneous. A special case of the above specification, which received attention in the existing literature, is when for every $j=1,2$ and $i \in[0,1]$, it holds that $g_{i}^{j}\left(N_{k}^{-j}\right)=u^{j} N_{k}^{-j}$ (i.e., consumers on the same side have the same linear utility function).

Because of the positive network externalities, there is typically a severe multiplicity of equilibria in the model presented above. We select among them by using an equilibrium refinement that allows players to coordinate their actions whenever coordination is in their joint interest and does not require communication. The formal concept we use is coalitional rationalizability (Ambrus 2006). This solution concept builds on the idea that groups of players, or coalitions, consider implicit agreements to restrict their play to a certain subset of the strategy space (to avoid playing some strategies). These implicit agreements need to be self-enforcing. Restrictions that are in the mutual interest of all coalition members are called "supported" restrictions. The set of coalitionally rationalizable strategies is defined by an iterative procedure of supported restrictions by all possible coalitions, starting from the set of all strategies. For the formal definition of coalitional rationalizability, see Appendix A.

In the forthcoming analysis, we restrict attention to pure strategy subgame perfect equilibria in which players play coalitionally rationalizable strategies in every subgame. We call these outcomes coalition perfect equilibria.

DEFINITION: A strategy profile is a coalition perfect equilibrium if it is a subgame perfect Nash equilibrium and every player plays some coalitionally rationalizable strategy in every subgame.

The games we analyze are such that there are no credible and mutually advantageous restrictions between two firms or between a firm and some consumers. However, coalition perfect equilibrium puts restrictions on consumers' beliefs concerning other consumers' choices after various network choice and price announcements by the firms, both on and off the equilibrium path. In particular, after certain price announcements, the concept implies that some consumers can successfully coordinate on joining the same network. This is the case when coordinating on one network is in some sense focal to the consumers. For example, if one network is cheaper on both sides of the market than the rest of the networks. ${ }^{20}$ In other subgames, coalition perfect equilibrium does not imply successful coordination by the consumers necessarily, even if they would all be better off by coordinating. This can

\footnotetext{
${ }^{20}$ See Appendix A for two examples on how coalitional rationalizability restricts action choices in consumer subgames.
} 
happen if one network is cheaper on one side of the market, while the other one is cheaper on the other side. Therefore, the concept we use assumes only a weak form of coordination.

There are ways to both strengthen and weaken the solution concept used without changing the qualitative results in the paper. A stronger concept in our context would be extensive form coalition-proof Nash equilibrium (Bernheim, Peleg, and Whinston 1987). ${ }^{21}$ A weaker concept that would lead to the same results could be obtained the following way. The set of coalitionally rationalizable strategies corresponds to a possibly infinite sequence of implicit coalitional agreements. Arguably, this requires too much sophistication in the reasoning procedure of consumers. However, because of the simple payoff structure of the games we examine, all our results would remain valid if we only required one round of coalitional agreements after eliminating nonrationalizable strategies.

The concept we use is not equivalent, in any sense, to requiring Pareto efficiency in consumer subgames. In consumer subgames, in which there is a unique Pareto efficient outcome, coalition perfect equilibrium implies that the efficient outcome is played. But in subgames with multiple Pareto efficient outcomes, it is consistent with coalition perfect equilibrium that a Pareto inefficient outcome is played. On the other hand, if consumers are heterogeneous, then not every Pareto efficient outcome is consistent with coalition perfect equilibrium. Pareto efficiency only checks whether a given outcome can be improved for the set of all players, while coalition perfect equilibrium takes into account that subgroups of players can coordinate as well, if it is in their best interest.

The concept we use is also substantially different from the selection criterion in Jullien (2001), which assumes that consumers coordinate on the equilibrium that is most favorable to one of the firms (the incumbent).22

\section{Monopolist Network Provider}

In this section, we assume that there is a monopolist network provider, and that the monopolist can decide whether to establish one or two platforms (to which we will refer as network 1 and network 2).

Our first theorem, which applies to any distribution of consumer preferences, will be useful in establishing the subsequent results.

The proofs of all theorems that are stated in the main section of the paper are in the Appendix.

\footnotetext{
${ }^{21}$ In general, there is no containment relationship between coalition perfect equilibrium and coalition-proof Nash equilibrium. In the games that we analyze though the latter (coalition-proof Nash equilibrium) implies more effective coordination on the part of consumers. This can lead to a strictly smaller set of equilibrium prices in our model than what is compatible with coalition perfect equilibrium.

${ }^{22}$ To get an intuition on how the implications of the two selection criteria differ in the context of two-sided markets, see Section VA. There we make a direct comparison, in a special context, between our results and those of Caillaud and Jullien (2001). The latter paper uses a selection criterion (full market coverage and monotonicity in prices) that is closely related to the one proposed by Jullien (2001).
} 
THEOREM 1: If there is a monopolist network provider, then the profit of the monopolist in a coalition perfect equilibrium is at least as much as the maximum possible profit attainable by the monopolist in Nash equilibrium with one network.

The intuition for this result is the following. Consider the most profitable Nash equilibrium, and let $N^{*}$ be the set of consumers joining the network in that equilibrium. Each consumer in $N^{*}$ must receive nonnegative utility. Therefore, if the monopolist charged any set of prices smaller than those in the most profitable Nash equilibrium, and all the consumers in $N^{*}$ joined the network, each of them would receive a strictly positive utility. Our assumption, that consumers can coordinate their network choices as long as their interests are aligned, implies that, in this case, the consumers in $N^{*}$ would join the network. In particular, the monopolist can announce prices arbitrarily close to the prices in the most profitable Nash equilibrium and still make sure that all consumers in $N^{*}$ join the network. Therefore, the monopolist can achieve any profit level arbitrarily close to the level in the most profitable Nash equilibrium.

\section{A. Homogeneous Consumers}

We show that if consumers are homogeneous, then a monopolist network provider always establishes only one network.

THEOREM 2: Assume that the reservation value of every consumer on side $j$ is $u^{j}($ for $j=1,2)$. Then in any coalition perfect equilibrium, the monopolist establishes only one active network and charges prices equal to the reservation values. Furthermore, all consumers join this network.

This result is a consequence of Theorem 1. By providing one network, the firm can extract the maximum possible gross consumer surplus in this market. If there are two active networks, then gross consumer surplus is smaller than in the above case, and since no consumer can get negative utility in any Nash equilibrium, the profit of the firm is strictly smaller than what it could obtain by establishing only one network. The assumption that consumers can implicitly coordinate their choices in this case ultimately hurts them because the firm can extract all the potential consumer surplus in the market.

\section{B. Two Types of Consumers on Both Sides}

In our model, there are several reasons to expect that a monopolist network provider always wants to establish only one network, even when consumers are heterogeneous. One is that the amount of revenue a monopolist can get from a consumer cannot be higher than the utility this consumer obtains from joining the network, and the utility of every consumer is larger if all consumers are on the same network than if they are divided into two networks. Second, our assumption that consumers have at least some ability to coordinate their choices when it is in their best interest to do so excludes the possibility that the monopolist establishes an expensive network for 
relatively high valuation consumers and a cheap one for low valuation consumers, since, then, all consumers would just choose the cheaper network. In this subsection, we show by example that, despite these arguments, a monopolist can find it feasible and profitable to divide the consumers and operate two active networks. We show that in this case, one network is cheaper and larger on one side of the market, while the other network is cheaper and larger on the other side. In the next subsection, we show that these qualitative features of equilibria with two networks generalize to any distribution of consumer preferences.

In the remainder of this subsection, we assume that there are only two types of consumers on each side, and consumers have linear utility functions.

Assume that $g_{i}^{j}(N)=u_{i}^{j} \cdot N \forall j=1,2$ and $i \in[0,1]$. Also assume that $u_{i}^{1}=u_{i}^{2}=h$ $\forall i \in[0, a]$ and $u_{i}^{1}=u_{i}^{2}=l \forall i \in(a, 1]$, where $l<h$ and $a \in(0,1)$.

On each side, a fraction $a$ of the consumers have a reservation value $h$, which is higher than $l$, the reservation value of the rest of the consumers. We refer to consumers with reservation value $h$ as high types, and consumers with reservation value $l$ as low types! 23

It is possible to prove that, in this context, a monopolist will never want to establish more than two networks. Below, we concentrate on the choice between establishing one versus two networks.

As a first step, we characterize the set of coalition perfect equilibria when the firm can only establish one network.

Define the following cutoff points:

$$
\begin{aligned}
t_{1} & \equiv 2 a-1 \\
t_{2} & \equiv \frac{a}{2-a} .
\end{aligned}
$$

Notice that if $a \geq 1 / 2$, then $0 \leq t_{1} \leq t_{2} \leq 1$, while if $a \leq 1 / 2$, then $t_{1} \leq 0 \leq t_{2} \leq 1 / 2$. Also, notice that both $t_{1}$ and $t_{2}$ are strictly increasing in $a$.

THEOREM 3: Assume the monopolist can only establish one network. For every coalition perfect equilibrium, the following holds:

(i) If $l / h<\max \left\{0, t_{1}\right\}$, then $p^{1}=p^{2}=a h$, and only the high types on both sides join the network.

(ii) If $l / h \in\left(\max \left\{0, t_{1}\right\}, t_{2}\right)$, then there is $j \in\{1,2\}$ such that $p^{j}=$ al, and on side $j$, all consumers join the network, while $p^{-j}=h$ and on side $-j$, only high types join the network.

\footnotetext{
${ }^{23}$ Note that high and low type only refer to the reservation value of consumers and not to their quality in terms of how desirable a consumer's presence is on the network for consumers on the other side. In our model, all consumers are ex ante identical in terms of this external effect.
} 
(iii) If $l / h \in\left(t_{2}, 1\right)$, then $p^{1}=p^{2}=l$, and all consumers on both sides join the network.

Finally, if $l / h=t_{1}$, there are coalition perfect equilibria of both type 1 and type 2 above. Similarly, if $l / h=t_{2}$, then there are coalition perfect equilibria of both type 2 and type 3 above.

The coalition perfect equilibrium is almost always unique, but depends on the values of parameters $a, h$, and $l$. If $l$ is relatively low and $a$ is high, then the monopolist targets only the high type consumers and charges a high price on both sides. If $l$ is relatively high and $a$ is small, then the monopolist targets all consumers and charges a low price on both sides. In cases in between, the monopolist might target all consumers on one side and only the high types on the other side, by charging a low and a high price. These results are both intuitive and in accordance with classic results from the literature on multi-product pricing with heterogeneous consumers.

Note that if $a<1 / 2$, then there is no coalition perfect equilibrium in which the monopolist charges a high price on both sides of the market, targeting only high types. Charging a high price on one side of the market has to be accompanied by charging a low price on the other side. The reason is that there must be enough consumers of the other side of the network for high types on the first side to be willing to pay the high price. The monopolist therefore cannot extract a high level of consumer surplus from both sides of the market simultaneously.

Assume now that the monopolist can choose to establish two networks. The next theorem shows that for a range of parameter values, in every coalition perfect equilibrium the monopolist chooses to operate two networks, and high- and low-type consumers on the same side of the market choose different networks.

Define the following cutoff points:

$$
\begin{aligned}
& z_{1} \equiv 4 a-1 \\
& z_{2} \equiv \frac{a(1-2 a)}{1-a} .
\end{aligned}
$$

Notice that if $a \in[0,1-\sqrt{2} / 2]$, then $t_{1} \leq z_{1} \leq t_{2} \leq z_{2}$, and both $z_{1}$ and $z_{2}$ are strictly increasing in $a$.

THEOREM 4: If $a \in(0,1-\sqrt{2} / 2)$ and $l / h \in\left(\max \left\{0, z_{1}\right\}, z_{2}\right)$, then the following hold for every coalition perfect equilibrium:

(i) The monopolist establishes two networks.

(ii) There is $j \in\{1,2\}$ such that all high types on side $j$ and all low types on side -j join network 1, while all low types on side $j$ and all high types on side $-j$ join network 2. The prices are $p_{1}^{j}=p_{2}^{-j}=h(1-2 a)+$ al and $p_{2}^{j}=p_{1}^{-j}=a l$. 
Note that this range of parameter values cuts into two regions. One, where a monopolist with one network would target all consumers on both sides, and another where he would target only high type consumers on one side and all consumers on the other.

By establishing two networks and pricing them differently, the monopolist implements a form of second-degree price discrimination. In particular, if

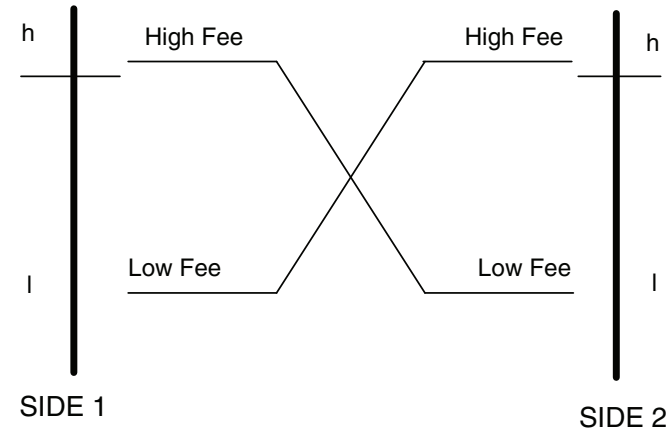

FIGURE 1 the proportion of high types is sufficiently low then, even if reservation values are unobservable, the monopolist can separate the low types and the high types on each side by charging a high price on side 1 and a low price on side 2 in one network and doing the opposite on the other network. An appropriate choice of prices results in low-type consumers choosing networks that are relatively cheap for them and high-type consumers choosing the ones that are relatively expensive for them. In equilibrium, the two networks, despite being physically equivalent, end up being of different quality. In our framework, the quality of a network for a consumer is determined by how many consumers join the network on the other side of the market. If the majority of consumers on each side of the market are low types, then when all low-type consumers on side 1 join one network, that network becomes higher quality for side 2 consumers. Similarly, when all low-type consumers on side 2 join one network, that network becomes higher quality for side 1 consumers. Since in the above equilibria the low type consumers join different networks, one network ends up being high quality for side 1 consumers, and the other for side 2 consumers. High-type consumers have a higher willingness to pay for quality and therefore are willing to join the networks that are more expensive for them.

The result that in equilibrium the monopolist separates consumers on the same side by offering them two products that have different prices and qualities is standard in the adverse selection literature ${ }^{24}$ What is special to this model is that the two networks are ex ante identical and that product differentiation is endogenous. The quality of a network is determined in equilibrium by the network choices of the consumers, which are driven by the prices of the networks.

The reason the monopolist might be better off using this type of price discrimination is that it can extract a large consumer surplus from high type consumers on both sides of the market simultaneously, something that it cannot achieve by operating only one network (see Figure 1 for an illustration).

In the above equilibrium, the firm sacrifices some gross consumer surplus (it would be socially efficient if all participating consumers were on the same network) in order to be able to extract a high share of the surplus from consumers with high reservation values on both sides of the market.

\footnotetext{
${ }^{24}$ See Michael Mussa and Sherwin Rosen (1978) and Eric Maskin and John Riley (1984).
} 
Despite this, the aggregate social welfare in the situation in which the monopolist is not allowed to operate multiple networks can be either higher or lower than in the situation in which it can only operate one. If $l / h \in\left(t_{2}, z_{2}\right)$, then a monopolist operating only one network charges prices $(l, l)$ and all consumers join the network. This generates a higher aggregate surplus than if the monopolist can operate two networks, because the same set of consumers participate in the market in both cases, but more surplus is generated if they all join the same network. As far as consumer surplus is concerned, high types are better off if the monopolist can run only one network and low types are indifferent (they get zero utility in both cases). On the other hand, if $l / h \in\left(z_{1}, t_{2}\right)$, then, being restricted to operate one network, the monopolist sets a price of $h$ on one side and la on the other. Only high types join the network on the first side, as well as all consumers from the other side. In this case, high-type consumers are better off if the monopolist can operate two networks and low-types are again indifferent. Furthermore, simple calculations show that aggregate social surplus is higher in the case of two networks.

Equilibrium prices and quantities have to satisfy the "incentive compatibility constraints" that require that a high-type consumer should prefer the more expensive network, while a low-type consumer should prefer the cheaper network. Furthermore, since staying out of the market is an option to every consumer, consumers have to get nonnegative utility in equilibrium — a "participation constraint." One feature of the above result, which is consistent with the literature on adverse selection, is that the incentive-compatibility constraints for the high types and the participation constraints for the low types are binding in equilibrium.

\section{General Results}

In the example presented in the previous subsection, equilibrium with two networks had a particular asymmetric structure. The next result establishes that this feature generalizes to any distribution of consumer preferences for which incremental utilities from increasing the number of consumers on the other side of the network are bounded by a positive constant.

THEOREM 5: Assume Al holds. If a monopolist establishes two active networks in a coalition perfect equilibrium, then one is (weakly) cheaper and larger on one side of the market, while the other is (weakly) cheaper and larger on the other side. Moreover, these relationships are strict at least on one side.

The intuition behind the result is that when consumers have some ability to coordinate their choices, when it is in their interest to do so, the monopolist cannot establish two active networks such that one is cheaper on both sides. If he did so, all consumers would just choose the cheaper network. Moreover, it is never in the interest of the monopolist to establish two networks and set the same prices, since the same consumers who join the two networks would be willing to pay higher prices if all of them were on the same network. The claim on equilibrium market shares follows from the asymmetry of prices and the rationality of consumers. 
The above result can be strengthened if we assume that consumers' utility functions are (weakly) convex.

THEOREM 6: Assume that the utility functions of all consumers are convex. If a monopolist establishes two active networks in a coalition perfect equilibrium, then one is strictly cheaper and larger on one side of the market, while the other is strictly cheaper and larger on the other side.

Whether a monopolist wants to establish multiple networks depends on the dispersion of consumer types. A necessary and sufficient condition is hard to characterize analytically, since the constraints implied by coalitional rationalizability can be very complicated if there are many consumer types. But for (weakly) convex utility functions, it is possible to provide a simple, necessary condition, in the form of an upper bound on the ratio of utilities of any two consumers on the same side, from joining the same network. In particular, if this ratio is always smaller than a particular threshold level (roughly 5.8), then the monopolist establishes only one network in equilibrium. We note that for concave utility functions, a smaller amount of heterogeneity might be enough for the existence of multiple networks in equilibrium. The intuition is that, if utility functions are more concave, then dividing consumers into different networks results in a smaller efficiency loss.

Define the dispersion of utility levels on side $j$ to be $\sup _{i, i^{\prime} \in[0,1], N \in(0,1]} g_{i}^{j}(N) / g_{i^{\prime}}^{j}(N)$.

THEOREM 7: If consumers' utility functions are convex, and the dispersion of utility levels on each sides of the market is less than $3+2 \sqrt{2}$, then the monopolist establishes only one active network in every coalition perfect equilibrium.

The key point in the proof is to show that, under the conditions of the theorem, establishing one network and charging prices equal to the lowest reservation value on each side is always more profitable than establishing two active networks. Establishing two active networks implies sacrificing some consumer surplus. Therefore, it can only be profitable if there are some consumers with sufficiently high reservation values relative to others.

We note that the results of this section carry over to the case when consumers can join multiple networks at the same time (multi-homing) ${ }^{25}$ Furthermore, the latter framework is formally equivalent to one in which the monopolist operates only one network but can sell restricted access to the network. Therefore, our results also imply that a monopolist in a two-sided market might want to sell limited access to consumers at a lower price and full access at a higher price on both sides of the market. This can occur in contexts in which it is technically feasible for the firm to control which transactions/matches can be made on the network, and if there is enough heterogeneity among consumers in how much they value the network effect.

\footnotetext{
${ }^{25}$ See Section VIB for a discussion.
} 


\section{Competing Network Providers}

In this section, we derive results for the case of competing network providers that are parallel to the theorems provided in the previous section for the case of a monopolist provider. In particular, multiple asymmetric networks can coexist in coalition perfect equilibrium, but only if there is sufficient heterogeneity among consumers.

\section{A. Homogenous Consumers}

In this subsection, we assume that there are two platform providers and that consumers on the same side have the same reservation value: $u^{1}$ on side 1 and $u^{2}$ on side 2 .

In Theorem 8, we show that either one firm attracts all consumers on both sides of the market, or the two firms charge the same prices and split the market equally, with each of them attracting half of the consumers on both sides. ${ }^{26}$ In both these configurations, the two firms make zero profits. Just like in the monopoly case, multiple asymmetric networks cannot coexist in equilibrium if consumers are homogenous.

THEOREM 8: If all consumers on the same side have the same reservation value, then there can be two types of coalition perfect equilibria in the duopoly game:

(i) All consumers join the same network $k$, which is priced such that $p_{k}^{1}=-p_{k}^{2}$;

(ii) Both networks attract half of the consumers on both sides, and prices are such that $p_{1}^{1}=p_{2}^{1}=-p_{1}^{2}=-p_{2}^{2}$.

The theorem reestablishes the zero-profit result in a symmetric Bertrand duopoly game for markets with network externalities. The intuition is that slightly undercutting the competitor's price on both sides results in stealing the whole market, since then we assume that consumers coordinate on the cheaper network. However, as opposed to a market with no network externalities, equilibrium prices are not necessarily equal to the marginal cost (assumed to be zero). It is possible that consumers on one side of the market are subsidized, and consumers on the other side pay a price that is equal to the subsidy received by the former group.

One feature that is common to all equilibria is that there is full consumer participation on both sides. If equilibrium prices are zero on both sides, then this follows from the assumption that consumers have some ability to limit coordination failures. If consumers do not join any network, each of them receives zero utility. If all consumers join some network instead, each of them expects a positive payoff, even if perfect coordination on just one network is not guaranteed. On the other hand, in the case where one side of the market is subsidized, then joining a network is clearly dominant for consumers on the subsidized side. Suppose now that at the same time not all consumers join the networks on the side where price is positive. Then one of

\footnotetext{
${ }^{26}$ It can be shown that imposing the stronger concept of extensive form coalition proof Nash equilibrium eliminates the second type of equilibrium. Therefore, when consumers are homogenous, all consumers join the same network in every extensive form coalition proof Nash equilibrium of the duopoly game.
} 
the networks could deviate profitably by slightly undercutting the market price on both sides and guarantee that all consumers from both sides (including the one with positive price) join its network, contradicting that the market is in equilibrium.

The next result establishes that if the reservation values on the two sides are not equal, then in every equilibrium the side with the smaller reservation value has to be subsidized 27

THEOREM 9: If $u^{j}<u^{-j}$ for $j \in\{1,2\}$, and in a coalition perfect equilibrium some consumers join network $k$, then $p_{k}^{j} \in\left[-u^{-j}, u^{j}-u^{-j}\right]$.

This result is not a consequence of coalitional rationalizability, but comes from the restrictions that "divide and conquer" strategies put on any subgame perfect Nash equilibrium ${ }^{28}$ If the market price is positive on the side with the low reservation value, then it is relatively cheap to steal consumers on that side, and then a higher price can be charged on the side with the high reservation value.

It is straightforward to use Theorems 8 and 9 to characterize the set of coalition perfect equilibria for the case when utility functions are linear.

CLAIM 1: $\operatorname{Let}_{i}^{j}\left(N^{-j}\right)=N^{-j} u^{j} \forall j=1,2$ and $i \in[0,1]$. Then the following holds:

(i) If $u^{j} \leq 2 u^{-j} \forall j=1,2$, then two types of coalition perfect equilibria exist:

- (monopoly equilibria with zero profits) all consumers join the same network $k, p_{k}^{l}=-p_{k}^{2}$, and $u^{j}<u^{-j}$ implies $p_{k}^{j} \leq u^{j}-u^{-j}$;

- (symmetric equilibria with zero profits) half of the consumers join each network on both sides, $p_{1}^{l}=p_{2}^{l}=-p_{1}^{2}=-p_{2}^{2}$, and $u^{j}<u^{-j}$ implies $p_{k}^{j} \leq u^{j}-$ $u^{-j}$.

(ii) If $u^{j}>2 u^{-j}$ for some $j \in\{1,2\}$, then only one type of coalition perfect equilibrium exists. (Monopoly equilibria with zero profits) all consumers join the same network $k, p_{k}^{l}=-p_{k}^{2}$, and $p_{k}^{j} \in\left[-u^{-j}, u^{j}-u^{-j}\right]$.

This linear and homogeneous specification is the same one considered in Caillaud and Jullien (2001). Therefore, Claim 1 gives an opportunity for a direct comparison of the results in a special setting. By assuming monotonicity of the demand function, Caillaud and Jullien obtain the same set of equilibria with two active firms. Their refinement, however, selects a larger set of equilibria with one active firm, including equilibria in which the active firm gets positive profits. Furthermore, full

\footnotetext{
${ }^{27}$ This asymmetric price structure, which entails one side being subsidized and the other being charged a positive price, is extremely common in two-sided markets. For a list of examples, see Rochet and Tirole (2003).

${ }^{28}$ The terminology "divide and conquer strategies" was introduced by Innes and Sexton (1993). Jullien (2001) and Caillaud and Jullien (2001) investigate these strategies in the context of price competition in two-sided markets. The main idea is that if a firm charges a sufficiently low (negative) price compared to its rival on one side of the market, it can make its network a dominant choice for consumers on that side. Then it can charge a high price on the other side of the market and still make sure that consumers join its network on that side. Despite the existence of these strategies, there typically is still a severe multiplicity of SPNE.
} 
participation is an extra assumption in their model, while it is implied by the same assumption (coalitional rationality) as the rest of the results in our model.

\section{B. Asymmetric Networks with Heterogeneous Consumers: An Example}

Below, we show that just like in the monopoly case, multiple asymmetric networks can emerge in equilibrium if there are two competing network providers. One interesting feature of this example is that the firms have positive profits in Bertrand competition, despite the assumption that consumers are coalitionally rational (which implies that each firm could "steal" all of the consumers from another firm by slightly undercutting its rival's prices on both sides of the market).

Consider the following specification. There are two firms in the market. All consumers have linear utility functions. Furthermore, on both sides of the market consumers' reservation values are distributed as follows:

- A mass of consumers with measure 0.4 have reservation value 2.55 (I types);

- A mass of consumers with measure 0.15 have reservation value 0.51 (II types);

- A mass of consumers with measure 0.1 have reservation value 0.46 (III types);

- A mass of consumers with measure 0.35 have reservation value 0.15 (IV types).

CLAIM 2: In the above game, there exists a coalition perfect equilibrium in which one firm charges a price of 0.31 on side 1 and -0.2 on side 2 , while the other firm charges -0.2 on side 1 and 0.31 on side 2 . All type I consumers on side 1 and type II-IV consumers on side 2 join the first firm, while all type I consumers on side 2 and type II-IV consumers on side 1 join the second firm.

Note that in this profile, both firms get a profit of $0.31 \times 0.4-0.2 \times 0.6=0.04$, which is strictly positive. The firms charge different prices, and consumers on the same side of the market with different reservation values end up paying different prices for the market good, despite the fact that reservation prices are private information of the consumers.

Every consumer on both sides of the market joins some network. Type I consumers on both sides of the market pay a registration fee of 0.31 for joining a network, and in equilibrium, they face a measure of 0.6 consumers from the other side of the market. All other consumers on both sides of the market are subsidized. They pay a registration fee of -0.2 . In the equilibrium, they face only a measure of 0.4 consumers from the other side of the market.

This equilibrium structure is similar to the equilibria in the previous section, in which the monopolist achieved price discrimination by operating two networks. In particular, one network is cheaper on one side of the market, while the other one is cheaper on the other side of the market. A larger fraction of consumers, those having relatively low reservation values, join the cheap network side, which makes it worthwhile for the remaining, high reservation value consumers to join the expensive network side. 
The reason why competition does not drive profits down to zero in the above example is that, with heterogeneous consumers, deviation strategies based on undercutting, while effective, are not necessarily profitable. For example, if firm 2 announces slightly cheaper prices than the equilibrium prices of firm 1, then types I-III from side 1 and all consumers from side 2 join its network. But the highest profit firm 2 can achieve this way is strictly smaller than the equilibrium profit of firm 1 . The reason is that the proposed undercutting increases the number of consumers joining the network by a larger amount on the side where the price is negative.

The same intuition applies to so-called "divide and conquer" type strategies. A firm can lower its price so that it makes it a dominant choice for some type of consumers to join its network, and then it can charge a high price on the other side of the market and still make sure that some consumers join its network on that side as well. But if consumers are heterogeneous, then the proportion of consumers who are willing to pay the increased price on the latter side might be too low to compensate for the costs associated with lowering the price (increasing the subsidy) on the first side.

\section{General Results}

In this subsection, we show that results similar to those in Section IVC can be established for the case of competing network providers as well. The first theorem establishes that for any distribution of consumer preferences, in any equilibrium with positive profits, the two competing networks have to be asymmetric (prices and market shares are different at least on one side), with the particular structure that one network is cheaper and larger on one side, and the other network is cheaper and larger on the other side. Unlike in the monopoly case, Assumption A1 is not needed to establish this result.

THEOREM 10: Suppose there are two firms in the market. If in a coalition perfect equilibrium the profit of at least one firm is positive, then one firm's network is (weakly) cheaper and larger on one side of the market, while the other firm's network is (weakly) cheaper and larger on the other side. Moreover, these relationships are strict at least on one side.

The reasons why equilibria with positive profit in the duopoly case and equilibria involving multiple networks in the monopoly case have the same asymmetric feature are not exactly the same. In both cases it cannot be that one network is cheaper on both sides of the market, since all consumers would choose this network. In the monopoly case, it is never in the interest of the firm to establish two networks that are priced equally, since that would just split consumers into two networks, generating less consumer surplus. In the duopoly case, there cannot be a coalition perfect equilibrium with positive profits and equally priced networks because of the usual Bertrand competition undercutting argument.

As in the case of a monopolist network provider, consumers need to be heterogeneous enough for the coexistence of two asymmetric active networks. The next theorem provides a necessary condition for multiple asymmetric networks 
to coexist in coalition perfect equilibrium. Theorem 10 implies that this is also a necessary condition for the existence of a coalition perfect equilibrium in which at least one firm obtains a positive profit. The condition is expressed in terms of the ratio of the highest and lowest reservation value for consumers on the same side. This ratio needs to be higher than a certain threshold, at least on one side. Note that this is a stronger requirement than the one that the dispersion of utilities (as defined in IVC) is higher than the same threshold on at least one side of the market.

THEOREM 11: Suppose there are two firms in the market. If consumers' utility functions are convex, and the ratio of reservation values of any two consumers on the same side is less than $4 / 3$, then there can be two types of coalition perfect equilibria:

(i) There is only one active network.

(ii) There are two active networks, priced the same and attracting the same number of consumers on both sides of the market.

\section{Discussion}

In this section, we discuss how the results of the paper would be affected by changing different assumptions we made in the model.

\section{A. Positive Marginal Cost}

If firms face a positive constant marginal cost, all the qualitative results still hold, with one exception. If the marginal cost is higher than a certain threshold, then, even if every consumer's reservation value is still higher than the marginal cost, it is not guaranteed that consumers can coordinate on entering the market. If marginal costs are high, then the average price charged on consumers is high, and ex ante coordination to join some network becomes harder.

\section{B. Multi-homing}

In some two-sided markets, network choices are naturally mutually exclusive, at least over a given period of time. For example, people looking for a date can only be in one entertainment facility at a time. In other contexts, consumers can join multiple platforms, which is called multi-homing in the literature.

The main conclusions of the paper remain valid if we allow for multi-homing. In particular, there can be multiple active networks in coalition perfect equilibrium that are not equally priced, provided that one network is cheaper and larger on one side of the market and the other network is cheaper and larger on the other side. In fact, if multi-homing is possible, then it is more likely that a monopolist finds it profitable to operate two networks rather than one. The intuition is that the monopolist can still set prices such that low reservation value consumers only join the network that is 
cheap on their side, but if multi-homing is allowed then high reservation value consumers on one of the two sides join both networks. This increases the monopolist's revenue, which makes dividing consumers into two networks more attractive, relative to establishing only one network.

\section{Conflict of Interest among Consumers on the Same Side}

The assumption that a consumer's utility is not affected by the number of consumers from the same side of the market who join the same platform can be restrictive in a variety of contexts. If the networks are matchmaking services or auction sites, then people on the same side of the market might compete for the same transactions. In other contexts, transactions are nonrival goods, validating our assumption of no conflict of interest on the same side.

It is possible to partially relax the assumption of no conflict of interest on the same side and retain some of the results in this paper. An earlier version of this paper shows that the results concerning markets with small amounts of heterogeneity hold even if some conflict of interest is allowed among consumers on the same side ${ }^{29}$ In particular, in this case, a monopolist always operates only one network in coalition perfect equilibrium, and there cannot be asymmetric active networks in duopoly competition either. In general, the existence of multiple networks in coalition perfect equilibrium becomes more likely if there is conflict of interest on the same side because the latter makes ex ante consumer coordination more difficult.

\section{More than Two Firms}

With more than two firms operating on the market, the analysis of the price competition game becomes complicated and therefore is omitted from this paper. However, we note that there can exist coalition perfect equilibria with multiple asymmetric networks in the case of more than two firms. In fact, in general there is a wider range of coalition perfect equilibria. The reason is that coordination among consumers is more difficult if there are more than two firms, hence there are less restrictions that apply to consumer choices after various price announcements.

\section{Conclusions and Possible Extensions}

This paper analyzes pricing decisions of firms and platform choices of consumers in two-sided markets with network externalities, in a context where consumers are heterogeneous with respect to how much they care about the externality. We show that this type of heterogeneity can lead to asymmetric market structures, with multiple differently priced networks coexisting in the market. We provide necessary conditions for this to be possible, and we derive qualitative properties of prices and market shares in these equilibria. A natural next step for future research would be to allow for different types of heterogeneity among consumers on these markets.

\footnotetext{
${ }^{29}$ Contact the authors for these extensions.
} 
Besides differences in preferences, consumers can be ex ante asymmetric with respect to the network externality they generate-their "attractiveness" to consumers on the other side. They might also be heterogeneous with respect to the marginal cost their transactions generate on the platforms they join. Both of these features would introduce interesting adverse selection problems in our model, which might be important in some two-sided markets.

\section{Appendix A: CoAlitional Rationalizability}

Some extra notation for the Appendix.

Let $C^{1}$ and $C^{2}$ denote the set of consumers on sides 1 and 2, and let $C=C^{1} \cup C^{2}$. Let $C_{i}^{j}$ denote consumer $i$ on side $j$.

Let $c_{i}^{j}$ denote the action choice of $C_{i}^{j}$. The set of possible choices for a consumer is $\{\emptyset, 1, \ldots, k\}$, where $k$ is the number of networks established and $\emptyset$ denotes the choice of not joining any network.

In the game with one firm, let $\pi_{M}$ denote the profit of the monopolist. In the duopoly game, let $\pi_{k}$ denote the profit of firm $k$ (for $k \in\{1,2\}$ ).

Let $S$ denote the set of strategies in the game. For every $s \in S$ let $\pi_{k}(s), p_{k}^{j}(s)$, $N_{k}^{j}(s)$, and $c_{i}^{j}(s)$ denote the realized $n_{k}, \pi_{k}, p_{k}^{j}, N_{k}^{j}$, and $c_{i}^{j}$ if profile $s$ is played.

Below, we provide the formal definition for coalitionally rationalizable strategies in consumer subgames.

Consider a consumer subgame after any sequence of network choices and price announcement by the firms. Let $S^{c}$ denote the strategy space in the subgame, and let $\left(S^{c}\right)_{i, j}$ denote the set of strategies of consumer $i$ on side $j$ in this subgame. Let $\mathcal{X}$ denote the collection of nonempty product subsets of $S^{c}$. For every $j=1,2$ and $i \in$ $[0,1]$, let $\Omega_{-i, j}$ be the set of probability distributions over $S_{-i, j}^{c}$. For every $A \in \mathcal{X}$, let $\Omega_{-i, j}(A)=\left\{\omega_{-i, j} \in \Omega_{-i, j}: \int_{a_{-i, j} \in A_{-i, j}} \omega_{-i, j}\left(a_{-i, j}\right)=1\right\}$. Finally, let $u_{i}^{j}\left(s_{i, j}, \omega_{-j, i}\right)$ denote the expected payoff of consumer $i$ on side $j$ in this subgame if he plays $s_{i, j}$ and his conjecture on other consumers' strategies is $\omega_{-i, j} \in \Omega_{-i, j}$.

DEFINITION: $B \in \mathcal{X}$ is a supported restriction by $J \subset C^{1} \cup C^{2}$ given $A \in \mathcal{X}$ if

(i) $B_{i, j}=A_{i, j}, \forall C_{i}^{j} \notin J$, and

(ii) $\forall C_{i}^{j} \in J$, and $\omega_{-i, j} \in \Omega_{-i, j}(A)$ for which $\exists s_{i, j} \in A_{i, j} / B_{i, j}$ such that $s_{i, j} \in$ $B R_{j}\left(\omega_{-i, j}\right)$, it is the case that

$$
u_{i}^{j}\left(s_{i, j}, \omega_{-j, i}\right)<\max _{t_{i}^{j} \in\left(S^{c}\right)_{i, j}} u_{i}^{j}\left(t_{i}^{j}, \tau_{-j, i}\right) \forall \tau_{-j, i} \text { such that } \tau_{-j, i} \in \Omega_{-j, i}(B) \text { and } \tau_{C / J}=\omega_{C / J} .
$$

The first condition above requires that only the strategies of those consumers who are members of the given coalition are restricted. The second condition requires that, for any player in the coalition, it holds that no matter what his beliefs are concerning the choices of consumers outside the coalition, his expected payoff is always strictly higher if the restriction is made (i.e., if every player in the coalition only chooses from among strategies in $B$ ) than if the restriction is not made, and it is rational for him to play some strategy outside the restriction. 
Let $\mathcal{F}(A)$ denote the set of supported restrictions (by any coalition $J$ ). Define now the following sequence of sets iteratively. Let $A^{0}=S^{c}$. For $k=1,2, \ldots$, let $A^{k}$ $=\bigcap_{B \in \mathcal{F}\left(A^{k-1}\right)} A^{k-1}$. The set of coalitionally rationalizable strategies in this consumer subgame is defined to be the intersection of this decreasing sequence of sets.

For a simple example, consider the following game specification. There are two firms, and for every $j=1,2$ and $i \in[0,1]$, it holds that $g_{i}^{j}\left(N^{-j}\right)=u N^{-j}$ for some constant $u>0$. Consider the subgame that follows price announcements $p_{1}^{j}=0$ and $p_{2}^{j}=u / 4 \forall j=1,2$. In other words, network 1 is cheaper than network 2 on both sides of the market. In this subgame, joining network 1 is a supported restriction for the coalition of all players, since it yields payoff $u$ to all consumers, while joining network 2 can only yield a payoff of at most $3 u / 4$ and staying out yields 0 . Therefore, the unique coalitionally rationalizable profile in this game is the one in which all consumers join network 1 .

If consumers are heterogeneous, then the set of coalitionally rationalizable outcomes in a subgame might be reached only after multiple rounds of agreements. Consider the following game specification. There are two firms, consumers have linear utility functions, $u_{i}^{1}=1 i \in[0,1 / 2], u_{i}^{1}=1 / 2 i \in(1 / 2,1]$, and $u_{i}^{2}=1 i \in[0,1]$. In other words, consumers on side 2 are homogeneous, while half of the consumers on side 1 have relatively low reservation values. Consider the subgame following price announcements $p_{1}^{1}=0.4, p_{1}^{2}=0.8$, and $p_{2}^{1}=0.8, p_{2}^{2}=0.4$. Initially, there is no supported restriction for the coalition of all consumers. Consumers would prefer to coordinate their network choices, but coordinating on network 1 is better for side 1 consumers, while coordinating on network 2 is better for side 2 consumers. However, note that joining network 2 is not rationalizable for any consumer $C_{i}^{1}$ for $i \in(1 / 2,1]$. Once it is established that players $C_{i}^{1}$ for $i \in(1 / 2,1]$ only consider the strategies, not joining any network or joining network 1 , it is a supported restriction for the coalition of all consumers to join network 1 .

\section{ApPendix B: Proofs}

\section{PROOF OF THEOREM 1:}

Using the fact that consumers' utility functions are continuous in the price of networks they join, it is straightforward to establish that there exists a Nash equilibrium with one network in which the monopolist's profit is higher than in any other Nash equilibrium with one network. Let $s$ be such a Nash equilibrium. Given that $g_{i}^{j}$ is strictly increasing for every $j \in\{1,2\}$ and $i \in[0,1], \pi_{M}(s)>0$. This implies that in $s$ at least on one side of the market the monopolist charges a strictly positive price and has a strictly positive market share. Let $\hat{C}^{j}(s)=\left\{C_{i}^{j}: c_{i}^{j}(s) \neq \emptyset\right\}$ for $j=1,2$. Then for $C_{i}^{j} \in \hat{C}^{j}(s)$ and $N^{j} \in[0,1]$, it holds that $g_{i}^{j}\left(N^{-j}(s)\right)-p^{j}(s)$ $\geq 0$. Then for every $\varepsilon>0$ and $C_{i}^{j} \in \hat{C}^{j}(s)$, it holds that $g_{i}^{j}\left(N_{1}^{-j}(s)\right)-p^{j}(s)+\varepsilon$ $>0$, which implies that if the monopolist establishes one network and sets prices $\left(p^{1}(s)-\varepsilon, p^{2}(s)-\varepsilon\right)$, in the resulting subgame joining the network is a supported restriction for $\hat{C}^{1}(s) \cup \hat{C}^{2}(s)$.

We use this result to show that the monopolist can get a profit arbitrarily close to $\pi_{M}(s)$ given that consumers are coalitionally rational. If $p^{j}(s) \geq 0$ for $j=1,2$, then the firm can get a profit arbitrarily close to $\pi_{M}(s)$ by establishing one network and charging 
prices $\left(p^{1}(s)-\varepsilon, p^{2}(s)-\varepsilon\right)$ for small enough $\varepsilon>0$. If $p^{j}(s)>0$ and $p^{-j}(s)<0$, it has to be the case that $N^{j}(s)>0$ and $N^{-j}(s)=1$. Then, by establishing one network and setting prices $\left(p^{1}(s)-\varepsilon, p^{2}(s)-\varepsilon\right)$, the monopolist gets market shares $N^{j} \geq N^{j}(s)$ and $N^{-j}=1$, and again its profit can be arbitrarily close to $\pi_{M}(s)$.

The above implies that the monopolist's profit in any coalition perfect equilibrium cannot be strictly lower than $\pi_{M}(s)$.

\section{PROOF OF THEOREM 2:}

It is easy to check that if the conditions of the theorem hold, then in the maximum profit Nash equilibrium with one network $p^{j}=u^{j}(j \in\{1,2\})$. Consider now a Nash equilibrium in which there are two networks and there is a positive fraction of consumers at both of them. Then for a positive fraction of consumers, it holds that the number of consumers on the other side of the same network is strictly less than 1. Without loss of generality, assume that $N_{1}^{1}>0$ and $N_{1}^{2}<1$ in the equilibrium at hand. Then $p_{1}^{1}<u^{1}$; otherwise consumers on side 1 would prefer not joining any network to joining network 1 . Furthermore, $N_{k}^{j}>0$ implies $p_{k}^{j} \leq u^{j}$ for $j, k \in\{1,2\}$, again because otherwise consumers on side $j$ would prefer not joining any network to joining network $k$. The above imply that $\pi_{M}<u^{1}+u^{2}$ in the Nash equilibrium at hand, so by Theorem 1 it cannot be a coalition perfect equilibrium.

\section{PROOF OF THEOREM 3:}

In the subgame following price announcements $(l, l)$, every consumer joining the network is a coalitionally rationalizable Nash equilibrium, which gives a profit of $2 l$ to the monopolist. In the subgame following price announcements $(a l, h)$, it is a coalitionally rationalizable Nash equilibrium if all consumers from side 1 and high types from side 2 join the network, which gives a profit of $a(h+l)$ to the monopolist. In the subgame following price announcements $(a h, a h)$, it is a coalitionally rationalizable Nash equilibrium if high types from both sides join the network, which gives a profit of $2 a^{2} h$ to the monopolist.

Suppose $2 a^{2} h>a l+a h$. Since $a>0$, this is equivalent to $(2 a-1) h>l$. The latter implies $a^{2} h>l$ since $a^{2} h-(2 a-1) h=(a-1)^{2} h>0$. Therefore $(2 a-1) h$ $>l$ implies that $2 a^{2} h>\max (2 l, a h+a l)$.

Suppose now that $a h+a l<2 l$. It is equivalent to $l>(a /(2-a)) h$. The latter implies $l>a^{2} h$ since $(a /(2-a)) h-a^{2} h=a h\left[\left(1-2 a+a^{2}\right) /(2-a)\right]>0$. Therefore $2 a^{2} h<2 l$. This establishes that if $l>(a /(2-a)) h$, then $2 l>\max \left(2 a^{2} h, a h+\right.$ $a l)$.

Note that $(2 a-1) h<(a /(2-a)) h$. If $l \in((2 a-1) h,(a /(2-a)) h)$, then $2 a^{2} h$ $<a l+a h$ and $a h+a l>2 l$ and therefore $a h+a l>\max \left(2 l, 2 a^{2} h\right)$.

It is straightforward to show that there is no Nash equilibrium in which $\pi_{M}$ is larger than $\max \left(2 l, 2 a^{2} h, a(h+l)\right)$. Then the theorem follows from the above results and Theorem 1.

\section{PROOF OF THEOREM 4:}

In any coalition perfect equilibrium, in the subgame following the firm establishing two networks and setting prices, $p_{1}^{1}=p_{2}^{2}=l a-\varepsilon, p_{1}^{2}=p_{2}^{1}=l a+(1-a) h-$ $2 \varepsilon(\varepsilon>0)$, it has to hold that $c_{i}^{1}=2, c_{i}^{2}=1 \forall i \in[0, a]$ and $c_{i}^{1}=1, c_{i}^{2}=2 \forall i \in(a, 1]$. 
To see this, define $A \subset S$ such that $A=\times_{i \in[0,1], j=1,2} A_{i}^{j}, A_{i}^{j} \equiv\{\emptyset, 1,2\} \forall i \in[0, a], j$ $=1,2, A_{i}^{1} \equiv\{\emptyset, 1\} \forall i \in(a, 1]$, and $A_{i}^{2} \equiv\{\emptyset, 2\} \forall i \in(a, 1]$. Also define $B \subset S$ such that $B=\times_{i \in[0,1], j=1,2} B_{i}^{j}$ and $B_{i}^{1} \equiv\{2\} \forall i \in[0, a], B_{i}^{2} \equiv\{1\} \forall i \in[0, a], j=1,2, B_{i}^{1}$ $\equiv\{1\} \forall i \in(a, 1]$, and $B_{i}^{2} \equiv\{2\} \forall i \in(a, 1]$. First note that for any $i \in[0,1]$ and $j \in$ $\{1,2\}, A_{i}^{j} \times S_{-1, i}$ is a supported restriction by $C_{i}^{j}$ given $S$, since strategies in $S_{i}^{j} / A_{i}^{j}$ are never best responses for consumer $i$ on side $j$. Next, $B$ is a supported restriction given $A$ by $C^{1} \cup C^{2}$ since it gives the best possible payoff to every consumer in this subgame, given $A$. Therefore $c_{i}^{1}=2, c_{i}^{2}=1 \forall i \in[0, a]$ and $c_{i}^{1}=1, c_{i}^{2}=2 \forall i \in$ $(a, 1]$ is the only coalitionally rationalizable strategy in the above subgame.

Since $\varepsilon$ can be arbitrarily small positive, the above establishes that if $s \in S$ is a coalition perfect equilibrium, then $\pi_{M}(s) \geq 2(l a+(1-a) a h) \equiv \pi^{*}$.

Suppose there exists a coalition perfect equilibrium $s \in S$ such that $\pi_{M}(s)>\pi^{*}$.

First suppose that the number of networks established by the firm in $s$ is 1 . If $l$ $\in((4 a-1) h,(a /(2-a)) h)$, then by Theorem 3, $\pi_{M}(s) \leq(l+h) a$. But for $l>$ $(4 a-1) h$, it holds that $(l+h) a<2(l a+(1-a) a h) \equiv \pi^{*}$, a contradiction. If $l$ $\in((a /(2-a)) h,[a(1-2 a) /(1-a)] h)$, then by Theorem $2 \pi_{M}(s) \leq 2 l$. But $l<$ $[a(1-2 a) /(1-a)] h$ implies $2 l<2(l a+(1-a) a h) \equiv \pi^{*}$, a contradiction. Next, suppose that the number of networks established by the firm in $s$ is 2 . It cannot be that $N_{k}^{j}(s)=0$ for some $j=1,2$ and $k=1,2$ since then either $N_{k}^{-j}(s)=0$ or $p_{k}^{-j}(s)$ $\leq 0$ (otherwise consumers choosing network $k$ in $s$ would get negative utility, contradicting that $s$ is a Nash equilibrium). In either case, $\pi_{M}(s)$ is smaller or equal to the supremum of profits attainable by a strategy in which the monopolist operates only one network. Then, as established above, $\pi_{M}(s)<\pi^{*}$. Therefore $N_{k}^{j}(s)>0 \forall$ $j=1,2$ and $k=1,2$.

Let $H^{j}$ and $L^{j}$ denote high and low type consumers on side $j$. Let $X_{k}^{j}$ denote the consumers on side $j$ who join network $k$ in $s$.

First we establish that it cannot be that for some $j=1,2$ both $X_{1}^{j} \cap L^{j}=\emptyset$ and $X_{2}^{j} \cap L^{j}=\emptyset$. If $X_{1}^{j} \cap L^{j}=\emptyset$ and $X_{2}^{j} \cap L^{j}=\emptyset \forall j=1,2$, then $\pi_{M}(s)<2 a^{2} h<\pi^{*}$. Otherwise, w.l.o.g. assume $X_{1}^{2} \cap L^{2}=\emptyset$ and $X_{2}^{2} \cap L^{2}=\emptyset$ and $X_{2}^{1} \cap L^{1} \neq \emptyset$. Let $\hat{p}^{1}$ $=\max \left(0, p_{1}^{1}(s)\left[N_{1}^{2}(s)+N_{2}^{2}(s)\right] / N_{2}^{2}(s)\right)$ and $\hat{p}^{2}=\max \left(0, p_{2}^{2}(s)\right)$. Consider a deviation $s^{\prime}$ by the firm such that the firm establishes one network and sets prices $p^{1}\left(s^{\prime}\right)$ $=\hat{p}^{1}-\varepsilon$ and $p^{2}\left(s^{\prime}\right)=\hat{p}^{2}-\varepsilon$. In the subgame following the above prices, it is a supported restriction for $X_{1}^{1} \cup X_{2}^{1} \cup X_{1}^{2} \cup X_{2}^{2}$ (note that $X_{2}^{1} \cap L^{1} \neq \emptyset$ and therefore $p_{1}^{1}(s)$ $\leq l N_{2}^{2}$ ) to choose 1 . Therefore, deviating this way the firm can get a profit arbitrarily close to $\pi^{\prime} \equiv \hat{p}^{1}\left(N_{1}^{1}(s)+N_{2}^{1}(s)\right)+\hat{p}^{2}\left(N_{1}^{2}(s)+N_{2}^{2}(s)\right)$. Let $\hat{\hat{p}}^{1}=\max \left(0, p_{1}^{2}(s)\left[N_{1}^{2}(s)\right.\right.$ $\left.\left.+N_{2}^{2}(s)\right] / N_{1}^{2}(s\}\right)$ and $\hat{\hat{p}}^{2}=\max \left(0, p_{1}^{2}(s)\right)$. Consider now deviation $s^{\prime \prime}$ by the firm such that one network is established, and priced such that $p^{1}\left(s^{\prime \prime}\right)=\hat{\hat{p}}^{1}-\varepsilon$ and $p^{2}\left(s^{\prime \prime}\right)=\hat{\hat{p}}^{2}$ $-\varepsilon$. In the subgame following the above prices, it is a supported restriction for $X_{2}^{1}$ $\cup X_{1}^{2} \cup X_{2}^{2}$ to choose 1 . Therefore, deviating this way the firm can get a profit arbitrarily close to $\pi^{\prime \prime} \equiv \hat{\hat{p}}^{1} N_{2}^{1}(s)+\hat{\hat{p}}^{2}\left(N_{1}^{2}(s)+N_{2}^{2}(s)\right)$. It is straightforward to verify that both $\pi^{\prime}+\pi^{\prime \prime}>2 \pi_{M}(s)$, and therefore at least one of the above deviations, yields higher profit than $\pi_{M}(s)$. And since $n_{A}\left(s^{\prime}\right)=1$ and $n_{A}\left(s^{\prime \prime}\right)=1$, it holds that $\pi^{\prime}<\pi^{*}$ and $\pi^{\prime \prime}<\pi^{*}$, and therefore $\pi_{M}(s)<\pi^{*}$.

Next, we establish that it cannot be that for some $j=1,2$ both, and $X_{1}^{j} \cap L^{j} \neq \emptyset$, and $X_{2}^{j} \cap L^{j} \neq \emptyset$. If $X_{1}^{j} \cap L^{j} \neq \emptyset$, and $X_{2}^{j} \cap L^{j} \neq \emptyset \forall j=1,2$, then $p_{k}^{j}(s) \leq l N_{k}^{-j}(s) \forall k$ $=1,2$ and $j=1,2$. Then $\pi_{M}(s)<2 l<\pi^{*}$. Otherwise w.l.o.g. assume $X_{1}^{1} \cap L^{1} \neq \emptyset$, 
$X_{2}^{1} \cap L^{1} \neq \emptyset$ and $X_{1}^{2} \cap L^{2} \neq \emptyset$. Then $\pi_{M}(s)<(h+l) N_{1}^{1}(s) N_{2}^{2}(s)+2 l N_{1}^{2}(s) N_{2}^{1}(s)$, since $p_{1}^{1}(s) \leq l N_{2}^{2}(s), p_{2}^{1}(s) \leq l N_{2}^{1}(s), p_{1}^{2}(s) \leq l N_{1}^{1}(s)$, and $p_{2}^{2}(s)<h N_{2}^{1}(s)$. Note that $(h+l) N_{2}^{2}(s)<(h+l) a<\pi^{*}$, and therefore $(h+l) N_{2}^{2}(s)<(h+l) N_{1}^{1}(s) N_{2}^{2}(s)+$ $2 l N_{1}^{2}(s) N_{2}^{1}(s)$. This implies $(h+l) N_{2}^{2}(s)<2 l N_{1}^{2}(s)<2 l$. Furthermore, $2 l<\pi^{*}$ and therefore $2 l<(h+l) N_{1}^{1}(s) N_{2}^{2}(s)+2 l N_{1}^{2}(s) N_{2}^{1}(s)$. This implies $2 l\left(1-N_{1}^{2}(s) N_{2}^{1}(s)\right)$ $<(h+l) N_{1}^{1}(s) N_{2}^{2}(s)$, which implies $2 l N_{1}^{1}(s)<(h+l) N_{1}^{1}(s) N_{2}^{2}(s)$, which implies $2 l$ $<(h+l) N_{2}^{2}(s)$, a contradiction.

Finally, we establish that it cannot be that for some $k=1,2$ both $X_{k}^{1} \cap L^{1} \neq \emptyset$ and $X_{k}^{2} \cap L^{2} \neq \emptyset$. Suppose otherwise. Then, as established above, $X_{-k}^{1} \cap L^{1}=\emptyset$ and $X_{-k}^{2} \cap L^{2}=\emptyset$, but $X_{-k}^{1} \neq \emptyset$ and $X_{-k}^{2} \neq \emptyset$. This implies $N_{k}^{-j}(s) l-p_{k}^{j}(s) \geq N_{-k}^{-j}(s) l-$ $p_{-k}^{j}(s) \forall j=1,2$ and $N_{k}^{-j}(s) h-p_{k}^{j}(s) \leq N_{-k}^{-j}(s) h-p_{-k}^{j}(s) \forall j=1,2$, which implies $p_{k}^{j}(s) \leq p_{-k}^{j}(s) \forall j=1,2$. Then $p_{k}^{j}(s)=p_{-k}^{j}(s)$ for some $j=1,2$. Furthermore, $p_{k}^{j}(s)$ $\leq N_{k}^{-j}(s) l<l$. Then it is straightforward to establish that one of the following deviations are profitable for the firm for small enough $\varepsilon$ : either establishing one network and setting prices $p=(l-\varepsilon, l-\varepsilon)$, or establishing one network and setting prices $p=\left(p_{-k}^{1}(s)-\varepsilon, p_{-k}^{2}(s)-\varepsilon\right)$.

The above implies $\exists k \in\{1,2\}$ such that $X_{k}^{1} \cap H^{1}=X_{k}^{1}$ and $X_{-k}^{2} \cap H^{2}=X_{k}^{2}$. W.l.o.g. let $k=1$.

Note that $p_{1}^{2}(s) \leq l N_{1}^{1}$ and $p_{2}^{1}(s) \leq l N_{2}^{2}(s)$ since $X_{1}^{2} \cap L^{2} \neq \emptyset, X_{2}^{1} \cap L^{1} \neq \emptyset$ and by definition no consumer can get negative utility in any subgame if $s$ is played. Then $h N_{1}^{2}(s)-p_{1}^{1}(s) \geq h N_{2}^{2}(s)-p_{2}^{1}(s)$ implies $p_{1}^{1}(s) \leq l N_{2}^{2}(s)+h\left(1-N_{2}^{2}(s)\right)$ and $h N_{2}^{1}(s)-p_{2}^{2}(s) \geq h N_{1}^{1}(s)-p_{1}^{2}(s)$ implies $p_{2}^{2}(s) \leq l N_{1}^{1}(s)+h\left(1-N_{1}^{1}(s)\right)$. This establishes that

$$
\pi_{M}(s) \leq l\left(N_{1}^{1}(s)+N_{2}^{2}(s)\right)+h\left(N_{1}^{1}(s)+N_{2}^{2}(s)-2 N_{1}^{1}(s) N_{2}^{2}(s)\right) .
$$

Note that $\left[\partial\left(l\left(N_{1}^{1}(s)+N_{2}^{2}(s)\right)+h\left(N_{1}^{1}(s)+N_{2}^{2}(s)-2 N_{1}^{1}(s) N_{2}^{2}(s)\right)\right)\right] / \partial N_{1}^{1}=h+l-$ $2 h N_{2}^{2}(s) \geq h+l-2 h a>0$ (since the starting assumptions imply $a<1 / 2$ ). Similarly, it holds that $\partial\left[\left(\left(l\left(N_{1}^{1}(s)+N_{2}^{2}(s)\right)+h\left(N_{1}^{1}(s)+N_{2}^{2}(s)-2 N_{1}^{1}(s) N_{2}^{2}(s)\right)\right)\right] / \partial N_{2}^{2}=h+\right.$ $l-2 h N_{1}^{1}(s) \geq h+l-2 h a>0$. Therefore $\pi_{M}(s)<l 2 a+h\left(2 a-2 a^{2}\right)=\pi^{*}$ unless $p_{1}^{2}(s)=p_{2}^{1}(s)=a l, N_{1}^{2}(s)=N_{2}^{1}(s)=1-a, p_{1}^{1}(s)=p_{2}^{2}(s)=l a+h(1-a)$ and $N_{1}^{1}(s)=N_{2}^{2}(s)=a$.

LEMMA 1: Consider a consumer subgame in which there are two networks, and prices are $\left(p_{1}^{1}, p_{1}^{2}\right)$ and $\left(p_{2}^{1}, p_{2}^{2}\right)$. If $p_{k}^{j}<p_{-k}^{j} \forall j=1,2$ for some $k \in\{1,2\}$, then $-k$ is not a coalitionally rationalizable strategy in the subgame for any consumer. If also $p_{k}^{j}<u_{i}^{j} \forall j \in\{1,2\}$ and $i \in[0,1]$, then $k$ is the unique coalitionally rationalizable strategy in the subgame for all consumers.

\section{PROOF OF LEMMA 1:}

Let $R_{-k}$ be the set of consumers for whom $-k$ is rationalizable in the subgame. Then $p_{k}^{j}<p_{-k}^{j} \forall j=1,2$ implies that the restriction $\{k\}$ is supported by $R_{-k}$ in the subgame. The second claim in the lemma then follows from the fact that $p_{k}^{j}<u_{i}^{j} \forall j$ $\in\{1,2\}$ and $i \in[0,1]$ implies $R_{-k}=C$. 
LEMMA 2: Assume there is one firm in the market. Suppose s is a coalition perfect equilibrium in which the monopolist establishes two networks. Then it cannot be that both $N_{1}^{1}(s) p_{1}^{1}(s)+N_{2}^{1}(s) p_{2}^{1}(s) \leq 0$ and $N_{1}^{2}(s) p_{1}^{2}(s)+N_{2}^{2}(s) p_{2}^{2}(s) \leq 0$. Similarly, it cannot be that both $N_{1}^{1}(s) p_{1}^{1}(s)+N_{1}^{2}(s) p_{1}^{2}(s) \leq 0$ and $N_{2}^{1}(s) p_{2}^{1}(s)+$ $N_{2}^{2}(s) p_{2}^{2}(s) \leq 0$.

\section{PROOF OF LEMMA 2:}

By Theorem 1, in any coalition perfect equilibrium the monopolist gets at least the maximum possible profit that can be obtained in equilibrium with one network. Simple arguments establish that the latter is larger than zero, which implies the claims.

\section{PROOF OF THEOREM 5:}

Let $s$ be a coalition perfect equilibrium such that the monopolist establishes two networks, and $N_{k}^{j}(s)>0 \forall j, k \in\{1,2\}$. By Lemma 5.1 there exists $j$ such that $p_{1}^{j}(s)$ $\geq p_{2}^{j}(s)$ and $p_{1}^{-j}(s) \leq p_{2}^{-j}(s)$.

Suppose that $p_{1}^{j}(s)=p_{2}^{j}(s)$ and $p_{1}^{-j}(s)=p_{2}^{-j}(s)$. Since $s$ is a Nash equilibrium and $N_{k}^{j}(s)>0 \forall j, k \in\{1,2\}$, it must be that $N_{1}^{1}(s)=N_{2}^{1}(s)$ and $N_{1}^{2}(s)=N_{2}^{2}(s)$. Then Lemma 5.2 implies that for small enough $\varepsilon>0$, it is profitable for the monopolist to deviate to establishing only one network and setting prices $p^{j}=\max \left(0, p_{1}^{j}(s)+\right.$ $\left.\delta^{j}\left(N_{1}^{-j}, 2 N_{1}^{-j}\right)\right)-\varepsilon, p^{-j}=\max \left(0, p_{1}^{-j}(s)+\delta^{-j}\left(N_{1}^{j}, 2 N_{1}^{j}\right)\right)-\varepsilon$, given that consumers are coalitionally rational in the resulting subgame (where $\delta^{j}()$ and $\delta^{-j}()$ denote the universal lower bounds on incremental utilities from A1). This is because given the above assumptions, all consumers who join some network in $s$ join network 1 after the prescribed deviation.

The above imply that there exists $j$ such that $p_{1}^{j}(s)>p_{2}^{j}(s)$ and $p_{1}^{-j}(s) \leq p_{2}^{-j}(s)$. Since $s$ is a Nash equilibrium and $N_{k}^{j}(s)>0 \forall j, k \in\{1,2\}$, it must be that $N_{1}^{-j}(s)>$ $N_{2}^{-j}(s)$ and $N_{1}^{j}(s) \leq N_{2}^{j}(s)$.

\section{PROOF OF THEOREM 6:}

Let $s$ be a coalition perfect equilibrium such that the monopolist establishes two networks, and $N_{k}^{j}(s)>0 \forall j, k \in\{1,2\}$. By Lemma 5.1 there exists $j$ such that $p_{1}^{j}(s)$ $\geq p_{2}^{j}(s)$ and $p_{1}^{-j}(s) \leq p_{2}^{-j}(s)$.

Suppose that $p_{1}^{j}(s)=p_{2}^{j}(s)$ and $p_{1}^{-j}(s)=p_{2}^{-j}(s)$. Since $s$ is a Nash equilibrium and $N_{k}^{j}(s)>0 \forall j, k \in\{1,2\}$, it must be that $N_{1}^{1}(s)=N_{2}^{1}(s)$ and $N_{1}^{2}(s)=N_{2}^{2}(s)$. Lemma 5.2 implies that at least one of $p_{1}^{j}(s)>0$ and $p_{1}^{-j}(s)>0$ holds. Then for small enough $\varepsilon>0$, it is profitable for the monopolist to deviate to establishing only one network and setting prices $p^{j}=2 p_{1}^{j}(s)-\varepsilon, p^{-j}=\max \left(0,2 p_{1}^{-j}(s)\right)-\varepsilon$, given that consumers are coalitionally rational in the resulting subgame. This is because given the above assumptions, all consumers who join some network in $s$ join network 1 after the prescribed deviation.

Suppose next that $p_{1}^{j}(s)=p_{2}^{j}(s) \equiv \hat{p}^{j}$ and $p_{1}^{-j}(s)>p_{2}^{-j}(s)$. Since $s$ is a Nash equilibrium and $N_{k}^{j}(s)>0 \forall j, k \in\{1,2\}$, it must be that $N_{1}^{-j}(s)=N_{2}^{-j}(s) \equiv N^{-j}$ and $N_{1}^{j}(s)>N_{2}^{j}(s)$. If $p_{1}^{-j}(s) \leq 0$, then Lemma 5.2 implies that a deviation which 
involves establishing one network and pricing it such that $p^{-j}=-\varepsilon, p^{j}=2 p_{1}^{j}(s)-\varepsilon$ is profitable for small enough $\varepsilon$, given that consumers are coalitionally rational in the resulting subgame. Therefore, it has to be that $p_{1}^{-j}(s)>0$. If $\left[N_{2}^{j}(s) / N_{1}^{j}(s)\right] p_{1}^{-j}(s)$ $>p_{2}^{-j}(s)$ then $\left(N_{1}^{j}(s)+N_{2}^{j}(s)\right) \hat{p}^{j}+2 p_{1}^{-j}(s) N^{-j}>N_{1}^{j}(s) \hat{p}^{j}+N_{2}^{j}(s) \hat{p}^{j}+p_{1}^{-j}(s) N^{-j}+$ $p_{2}^{-j}(s) N^{-j}$.

Note that the right-hand side of the above inequality is the profit the monopolist gets in $s$, while the left-hand side is a profit level that can be approximated arbitrarily closely by a deviation in which the monopolist establishes one network and sets prices such that $p^{j}=\hat{p}^{j}-\varepsilon, p^{-j}=\left\{\left[N_{1}^{j}(s)+N_{2}^{j}(s)\right] / N_{1}^{j}(s)\right\} p_{1}^{-j}(s)-\varepsilon$, given that consumers are coalitionally rational in the resulting subgame and utility functions are convex. This is because the above assumptions imply that all consumers on side $j$ who join network 1 in $s$ join network 1 after the above deviation too. This contradicts that $s$ is a coalition perfect equilibrium. Therefore, it has to be that $\left[N_{2}^{j}(s) / N_{1}^{j}(s)\right] p_{1}^{-j}(s) \leq p_{2}^{-j}(s)$. Note that this in particular implies $p_{2}^{-j}(s)>0$. Then

$$
\begin{gathered}
2 N_{1}^{j}(s) p^{j}+2 N_{2}^{j}(s) p^{j}+N_{1}^{-j}(s) p_{2}^{-j}(s) \frac{N_{1}^{j}(s)+N_{2}^{j}(s)}{N_{2}^{j}(s)}+N_{2}^{-j}(s) p_{2}^{-j}(s) \frac{N_{1}^{j}(s)+N_{2}^{j}(s)}{N_{2}^{j}(s)} \\
>N_{1}^{j}(s) p^{j}+N_{2}^{j}(s) p^{j}+p_{1}^{-j}(s) N^{-j}+p_{2}^{-j} N^{-j} .
\end{gathered}
$$

Note that the right-hand side of this inequality is the profit the monopolist gets in $s$, while the left-hand side is a profit level that can be approximated arbitrarily closely by a deviation in which the monopolist establishes one network and sets prices such that $p^{j}=2 \hat{p}^{j}-\varepsilon, p^{-j}=p_{2}^{-j}(s)\left[N_{1}^{j}(s)+N_{2}^{j}(s)\right] / N_{2}^{j}(s)-\varepsilon$, given that consumers are coalitionally rational in the resulting subgame and utility functions are convex (implying that all consumers on side $j$ who join some network in $s$ join network 1 after the above deviation).

This concludes that there exists $j$ such that $p_{1}^{j}(s)>p_{2}^{j}(s)$ and $p_{1}^{-j}(s)<p_{2}^{-j}(s)$. Then equilibrium conditions for the consumers imply $N_{1}^{j}(s)<N_{2}^{j}(s)$ and $N_{1}^{-j}(s)>$ $N_{2}^{-j}(s)$.

\section{PROOF OF THEOREM 7:}

Suppose $\exists s \in S$ such that $s$ is a coalition perfect equilibrium in which the monopolist establishes two networks and $N_{k}^{j}(s)>0 \forall j \in\{1,2\}$ and $k \in\{A, B\}$.

By Theorem $6 \exists k \in\{1,2\}$ such that $p_{k}^{1}(s)<p_{-k}^{1}(s)$ and $p_{k}^{2}(s)>p_{-k}^{2}(s)$. Let $l^{1}=\left(N_{k}^{1}(s)+N_{-k}^{1}(s)\right) \inf _{i \in[0,1]: c_{i}^{j}(s)=k} g_{i}^{1}\left(N_{k}^{2}(s)+N_{-k}^{2}(s)\right), h^{1}=\left(N_{k}^{1}(s)+\right.$ $\left.N_{-k}^{1}(s)\right) \inf _{i \in[0,1]: c_{i}^{j}(s)=-k} g_{i}^{1}\left(N_{k}^{2}(s)+N_{-k}^{2}(s)\right), l^{2}=\left(N_{k}^{2}(s)+N_{-k}^{2}(s)\right) \inf _{i \in[0,1]: c_{i}^{i}(s)=-k}$ $g_{i}^{2}\left(N_{k}^{1}(s)+N_{-k}^{1}(s)\right)$ and let $h^{2}=\left(N_{k}^{2}(s)+N_{-k}^{2}(s)\right) \inf _{i \in[0,1]: c_{i}^{j}(s)=k} g_{i}^{2}\left(N_{k}^{1}(s)+\right.$ $\left.N_{-k}^{1}(s)\right)$. Since $s$ is a Nash equilibrium and utility functions are convex, $p_{k}^{1}(s)$ $\left.\leq\left[1 /\left(N_{k}^{1}(s)+N_{-k}^{1}(s)\right)\right]\right]^{1}\left[N_{k}^{2}(s) /\left(N_{k}^{2}(s)+N_{-k}^{2}(s)\right)\right]$ and $p_{-k}^{2}(s) \leq\left[1 /\left(N_{k}^{2}(s)+\right.\right.$ $\left.\left.N_{-k}^{2}(s)\right)\right] l^{2}\left[N_{k}^{1}(s) /\left(N_{k}^{1}(s)+N_{-k}^{1}(s)\right)\right]$ (otherwise consumers on side 1 who join $k$ and consumers on side 2 who join $-k$ in $s$ would be better off not joining any network). Similarly, $p_{-k}^{1}(s) \leq\left[1 /\left(N_{k}^{1}(s)+N_{-k}^{1}(s)\right)\right] h^{1}\left[N_{-k}^{2}(s)-N_{k}^{2}(s)\right] /\left[N_{k}^{2}(s)+N_{-k}^{2}(s)\right]+$ $p_{k}^{1}(s)$ and $p_{k}^{2}(s) \leq\left[1 /\left(N_{k}^{2}(s)+N_{-k}^{2}(s)\right)\right] h^{2}\left[N_{k}^{1}(s)-N_{-k}^{1}(s)\right] /\left[N_{k}^{1}(s)+N_{-k}^{1}(s)\right]+p_{-k}^{2}(s)$ 
(otherwise consumers on side 1 who join $-k$ and consumers on side 2 who join $k$ in $s$ would be better off switching networks). Let $x^{1}=N_{-k}^{1}(s) /\left(N_{k}^{1}(s)+N_{-k}^{1}(s)\right)$ and $x^{2}=N_{k}^{2}(s) /\left(N_{-k}^{2}(s)+N_{k}^{2}(s)\right)$. Then $\pi_{M}(s) \leq x^{2} l^{1}\left(1-x^{1}\right)+\left(\left(1-2 x^{2}\right) h^{1}+x^{2} l^{1}\right) x^{1}+$ $x^{1} l^{2}\left(1-x^{2}\right)+\left(\left(1-2 x^{1}\right) h^{2}+x^{1} h^{2}\right) x^{2}=h^{1} x^{1}+h^{2} x^{2}+l^{1} x^{2}+l^{2} x^{1}-2 h^{1} x^{1} x^{2}-$ $2 h^{2} x^{1} x^{2}$. It is easy to verify that the latter expression is maximized at $x_{1}=\left(h^{2}+\right.$ $\left.l^{1}\right) /\left(2 h^{1}+2 h^{2}\right), x_{2}=\left(h^{1}+l^{1}\right) /\left(2 h^{1}+2 h^{2}\right)$. Substituting these values into the expression yields $\pi_{M}(s) \leq\left[\left(h^{1}+l^{2}\right)\left(h^{2}+l^{1}\right)\right] / 2\left(h^{1}+h^{2}\right)$.

Let $\hat{C}(s)=\left\{C_{i}^{j} \in C: c_{i}^{j}(s) \neq \emptyset\right\}$. Consider a deviation by the monopolist in which only one network is established and prices are set such that $p^{j}=\left[1 /\left(N_{k}^{j}(s)+N_{-k}^{j}(s)\right)\right] l^{j}$ $-\varepsilon \forall j \in\{1,2\}$, where $\varepsilon>0$. The profit of the monopolist after this deviation is at least $l^{1}+l^{2}-\varepsilon\left(\sum_{j=1,2} \sum_{k=1,2} N_{k}^{j}(s)\right)$, given that consumers play coalitionally rationalizable strategies in the resulting subgame and their utility functions are convex (since then joining the network is a supported restriction for the coalition $\hat{C}(s)$ ). Since $\varepsilon$ can be taken arbitrarily small, the above implies that $\pi_{M}(s) \geq l^{1}+l^{2}$, which can only be if $\left[\left(h^{1}+l^{2}\right)\left(h^{2}+l^{1}\right)\right] / 2\left(h^{1}+h^{2}\right) \geq l^{1}+l^{2}$.

It is straightforward to verify that for any $h^{1}+h^{2}=h>0$ and $l^{1}+l^{2}=l>0$ the expression $\left[\left(h^{1}+l^{2}\right)\left(h^{2}+l^{1}\right)\right] / 2\left(h^{1}+h^{2}\right)-l^{1}-l^{2}$ is maximized at $h^{1}=h^{2}=h / 2$, $l^{1}=l^{2}=l / 2$. In that case, $\left[\left(h^{1}+l^{2}\right)\left(h^{2}+l^{1}\right)\right] / 2\left(h^{1}+h^{2}\right)-l^{1}-l^{2}=h^{2}-6 h l+$ $l^{2}$. Hence, a coalition perfect equilibrium with two active networks can only exist if $h^{2}-6 h l+l^{2} \geq 0$. Given that $h>l$, this implies $h \geq(3+2 \sqrt{2}) l$. Therefore, if the dispersion of utilities on both sides of the market is less than $(3+2 \sqrt{2})$, then there cannot exist a coalition perfect equilibrium with two active networks.

LEMMA 3: Let there be two firms in the market. In the subgame following price announcements $(0,0)(0,0)$ strategy $\emptyset$ is not coalitionally rationalizable for any $C_{i}^{j}$ $\in C$.

\section{PROOF OF LEMMA 3:}

In this subgame, $\{1,2\}$ is a supported restriction for $C$, since for any consumer (on either side of the market) and for any belief the consumer might have that is compatible with all other consumers playing according to the restriction, at least one of 1 or 2 gives a strictly positive payoff, while $\emptyset$ gives a zero payoff.

LEMMA 4: Let there be two firms in the market, and assume that $\mathrm{s}$ is a coalition perfect equilibrium. If $N_{1}^{j}(s)>0$ for some $j \in\{1,2\}$ and $N_{2}^{1}(s)=N_{2}^{2}(s)=0$, then (i) $p_{1}^{1}(s)=-p_{1}^{2}(s)$, (ii) $p_{1}^{j}(s) \leq u^{j} \forall j \in\{1,2\}$ and (iii) $N_{1}^{1}(s)=N_{1}^{2}(s)=1$. Similarly, if $N_{2}^{j}(s)>0$ for some $j \in\{1,2\}$ and $N_{1}^{1}(s)=N_{1}^{2}(s)=0$, then (i) $p_{2}^{1}(s)=-p_{2}^{2}(s)$, (ii) $p_{2}^{j}(s) \leq u^{j} \forall j \in\{1,2\}$ and (iii) $N_{2}^{1}(s)=N_{2}^{2}(s)=1$.

\section{PROOF OF LEMMA 4:}

Note that $N_{2}^{1}(s)=N_{2}^{2}(s)=0$ implies $\pi_{2}(s)=0$. Suppose $p_{1}^{j}(s)>u^{j}$ for some $j \in$ $\{1,2\}$. Then $N_{1}^{j}(s)=0$ since consumers cannot get negative utility in $s$. Then $N_{1}^{-j}(s)$ $>0$ implies that $p_{1}^{-j}(s) \leq 0$, again because consumers cannot get negative utility in $s$. Since firm 1 cannot have negative profit in $s$, this implies $p_{1}^{-j}(s)=0$. Consider the deviation $\left(u^{1}-\varepsilon,-\varepsilon\right)$ by firm 2 , where $\varepsilon>0$. In the subgame following this deviation it is a supported restriction for $C^{1} \cup C^{2}$ to play 2, because that profile yields 
the highest possible payoff in this subgame for every $C_{i}^{j} \in C$, and choosing 1 or $\emptyset$ yields a strictly smaller payoff than this maximum no matter what strategies other consumers play. Then if consumers are coalitionally rational, firm 2's profit after this deviation is $u-2 \varepsilon$, which is positive for small enough $\varepsilon$. This contradicts that $s$ is an equilibrium. This concludes that $p_{1}^{j}(s) \leq u^{j} \forall k=1,2$.

Suppose now that $p_{1}^{1}(s)+p_{1}^{2}(s)>0$. Consider the deviation $\left(p_{1}^{1}(s)-\varepsilon, p_{1}^{2}(s)-\varepsilon\right)$ by firm 2, where $\varepsilon>0$. By Lemma 5.1 after this deviation all consumers choose 2 , therefore firm 2's profit is $p_{1}^{1}(s)+p_{1}^{2}(s)-2 \varepsilon$, which is positive for small enough $\varepsilon$, a contradiction. This concludes that $p_{1}^{1}(s)+p_{1}^{2}(s) \leq 0$.

Suppose now that $p_{1}^{1}(s)+p_{1}^{2}(s)<0$. This implies $p_{1}^{j}(s)<0$ for some $j \in\{1,2\}$. Then $N_{2}^{j}(s)=0$ implies $N_{1}^{j}(s)=1$, since 1 strictly dominates $\emptyset$ for side 1 consumers. But then $p_{1}^{1}(s)+p_{1}^{2}(s)<0$ implies $\pi_{1}(s)=p_{1}^{1}(s) N_{1}^{1}(s)+p_{1}^{2}(s) N_{1}^{2}(s)<0$, a contradiction. This concludes that $p_{1}^{1}(s)+p_{1}^{2}(s)=0$.

Consider now $p_{1}^{1}(s)=p_{1}^{2}(s)=0$. Then $\pi_{1}(s)=0$. If $p_{2}^{j}(s)<0$ for some $j \in\{1,2\}$, then $\emptyset$ is a strictly dominated strategy for side $j$ consumers, and therefore $N_{2}^{j}(s)=0$ implies $N_{1}^{j}(s)=1$. Then choosing 1 yields utility $u^{-j}>0$ for side $-j$ consumers, and therefore $N_{2}^{-j}(s)=0$ implies $N_{1}^{-j}(s)=1$. Suppose now that $p_{2}^{1}(s)>0$ and $p_{2}^{2}(s)=0$. Then by Lemma 5.1, a deviation $\min \left(u-\varepsilon, p_{B}^{1}(s)-\varepsilon\right),-\varepsilon$ by firm 1 for $\varepsilon>0$ guarantees that all consumers choose 1 , which for small enough $\varepsilon$ yields positive profit for firm 1, contradicting that $s$ is an equilibrium. A symmetric argument rules out that $p_{2}^{1}(s)=0$ and $p_{2}^{2}(s)>0$. If $p_{2}^{1}(s)=p_{2}^{2}(s)=0$, then Lemma 8.1 implies that $N_{1}^{j}(s)+$ $N_{2}^{j}(s)=1 \forall j \in\{1,2\}$, and then $N_{2}^{1}(s)=N_{2}^{2}(s)=0$ implies $N_{1}^{1}(s)=N_{1}^{2}(s)=1$.

LEMMA 5: Let there be two firms in the market, and assume that $u_{i}^{j}=u^{j} \forall j \in\{1,2\}$ and $i \in[0,1]$. Let $\mathrm{s}$ be a coalition perfect equilibrium such that $N_{1}^{j}(s)>0$ for some $j \in\{1,2\}$ and $N_{2}^{j}(s)>0$ for some $j \in\{1,2\}$. Then $p_{1}^{1}(s)=p_{2}^{1}(s)=-p_{1}^{2}(s)=-p_{2}^{2}(s)$ and $p_{1}^{j}(s) \leq u^{j} \forall j \in\{1,2\}$. Moreover, $N_{1}^{1}(s)=N_{1}^{2}(s)=N_{2}^{1}(s)=N_{2}^{2}(s)=1 / 2$.

\section{PROOF OF LEMMA 5:}

Suppose $p_{k}^{j}(s)>u^{j}$ for some $j, k \in\{1,2\}$. W.l.o.g. assume $p_{1}^{1}(s)>u^{1}$. Then $N_{1}^{1}(s)$ $=0$ and therefore $N_{1}^{2}(s)>0$. This is only compatible with $s$ being a Nash equilibrium if $p_{1}^{2}(s)=0$. Then by Lemma 5.1 a price announcement $\left(u^{1}-\varepsilon,-\varepsilon\right)$ by firm 2 for $\varepsilon>0$ guarantees that all consumers choose 2, which for small enough $\varepsilon$ yields positive profit for firm 2 . Therefore $\pi_{1}(s)=0$ and $\pi_{2}(s)>0$. The latter can only be if both $N_{2}^{1}(s)>0$ and $N_{2}^{2}(s)>0$, which imply that $p_{2}^{j}(s)<u^{j} \forall j \in\{1,2\}$. Then by Lemma 5.1, a deviation $\left(p_{2}^{1}(s)-\varepsilon, p_{2}^{2}(s)-\varepsilon\right)$ by firm 1 for $\varepsilon>0$ guarantees that all consumers choose 1 . For small enough $\varepsilon$, this deviation profit is close to $p_{2}^{1}(s)+$ $p_{2}^{2}(s)$. If $p_{2}^{j}(s) \geq 0 \forall j \in\{1,2\}$, then $\pi_{2}(s)>0$ implies $p_{2}^{1}(s)+p_{2}^{2}(s)>0$, which implies that the above deviation is profitable for small enough $\varepsilon$. If $p_{2}^{2}(s) \leq 0$, then $\pi_{2}(s)>0$ implies $N_{2}^{1}(s)>0$, but then $N_{1}^{2}(s)>0$ contradicts that every consumer plays a best response in $s$. Therefore $p_{2}^{2}(s)>0$. If $p_{2}^{1}(s)<0$ and $p_{2}^{2}(s)>0$, then $N_{2}^{1}(s)=1$ since 2 is the unique best response after the equilibrium price announcements for side 1 consumers, and therefore $p_{2}^{1}(s)+p_{2}^{2}(s) \geq p_{2}^{1}(s) N_{2}^{1}(s)+p_{2}^{2}(s) N_{2}^{2}(s)$ $=\pi_{2}(s)>0$. This implies that the above deviation for firm 1 is profitable for small enough $\varepsilon$, contradicting that $s$ is a Nash equilibrium. This concludes that $p_{k}^{j}(s) \leq u^{j}$ $\forall j, k \in\{1,2\}$. 
Suppose $p_{1}^{j}(s) \neq p_{2}^{j}(s)$ for some $j \in\{1,2\}$. W.l.o.g. assume $p_{1}^{1}(s)>p_{2}^{1}(s)$. Then $p_{1}^{2}(s) \leq p_{2}^{2}(s)$, otherwise Lemma 5.1 implies $N_{1}^{1}(s)=N_{1}^{2}(s)=0$. Suppose first that $N_{1}^{1}(s)=N_{2}^{1}(s)=0$. Then $N_{1}^{2}(s)>0$ and $N_{2}^{2}(s)>0$. This is only compatible with consumers being in equilibrium and firms not getting negative profit if $p_{1}^{2}(s)=p_{2}^{2}(s)$ $=0$. Then $\pi_{2}(s)=0$. Then by Lemma 5.1, a deviation $\min \left(u-\varepsilon, p_{1}^{1}(s)-\varepsilon\right),-\varepsilon$ by $B$ for $\varepsilon>0$ guarantees that all consumers choose 1, which for small enough $\varepsilon$ yields positive profit for firm 2, contradicting that $s$ is an equilibrium. Suppose next that $N_{1}^{2}(s)=N_{2}^{2}(s)=0$. Then $N_{1}^{1}(s)>0$ and $N_{2}^{1}(s)>0$, which contradicts that $s$ is a Nash equilibrium, since $N_{1}^{2}(s)=N_{2}^{2}(s)=0$ and $p_{1}^{1}(s)>p_{2}^{1}(s)$ implies that for any consumer on side 1, given the other players' strategies, 2 is a better response than 1 in the subgame following the equilibrium price announcements in $s$. This concludes that $N_{k}^{1}(s)>0$ for some $k \in\{1,2\}$ and $N_{k}^{1}(s)>0$ for some $k \in\{1,2\}$. Then $N_{1}^{1}(s)$ $\leq N_{2}^{1}(s)$ and $N_{1}^{2}(s)>N_{2}^{2}(s)$, otherwise $p_{1}^{1}(s)>p_{2}^{1}(s)$ and $p_{1}^{2}(s) \leq p_{2}^{2}(s)$ imply that some consumers are not playing a best response in $s$. Consider now following two deviations. The first is $\left(p_{2}^{1}(s)-\varepsilon, p_{2}^{2}(s)-\varepsilon\right)$ by firm 1 , and the second is $\left(p_{1}^{1}(s)-\right.$ $\varepsilon, p_{1}^{2}(s)-\varepsilon$ ) by firm 2. Since $p_{k}^{j}(s) \leq u^{k} \forall j, k \in\{1,2\}$, Lemma 5.1 implies that after the first deviation all consumers choose 1 , and after the second deviation all consumers choose 2 . Then the first deviation yields a profit $p_{2}^{1}(s)+p_{2}^{2}(s)-2 \varepsilon$ to firm 1 , while the second one yields $p_{1}^{1}(s)+p_{1}^{2}(s)-2 \varepsilon$ to firm 2 . The sum of these deviation profits is $p_{1}^{1}(s)+p_{1}^{2}(s)+p_{2}^{1}(s)+p_{2}^{2}(s)-4 \varepsilon$. The sum of the two firms' equilibrium profits is $N_{1}^{1}(s) p_{1}^{1}(s)+N_{1}^{2}(s) p_{1}^{2}(s)+N_{2}^{1}(s) p_{2}^{1}(s)+N_{2}^{2}(s) p_{2}^{2}(s) \equiv \pi^{*}$. Note that $p_{2}^{1}(s)<0$ implies that $N_{1}^{1}(s)+N_{1}^{2}(s)=1$, since then $\emptyset$ is never a best response for any consumer on side 1. Similarly, $p_{1}^{2}(s)<0$ implies that $N_{2}^{1}(s)+N_{2}^{2}(s)=1$. Then by $N_{1}^{1}(s) \leq N_{2}^{1}(s)$, $N_{1}^{2}(s)>N_{2}^{2}(s), p_{1}^{1}(s)>p_{2}^{1}(s)$, and $p_{1}^{2}(s) \leq p_{2}^{2}(s)$, it has to hold that $N_{1}^{1}(s) p_{1}^{1}(s)+$ $N_{1}^{2}(s) p_{1}^{2}(s)+N_{2}^{1}(s) p_{2}^{1}(s)+N_{2}^{2}(s) p_{2}^{2}(s)<1 / 2\left(p_{1}^{1}(s)+p_{1}^{2}(s)+p_{2}^{1}(s)+p_{2}^{2}(s)\right)$. The left hand side of this inequality is nonnegative (it is the sum of equilibrium profits); therefore the right hand side is positive, which implies that also $N_{1}^{1}(s) p_{2}^{1}(s)+N_{1}^{2}(s) p_{1}^{2}(s)+$ $N_{2}^{1}(s) p_{2}^{1}(s)+N_{2}^{2}(s) p_{2}^{2}(s)<p_{1}^{1}(s)+p_{1}^{2}(s)+p_{2}^{1}(s)+p_{2}^{2}(s)$. This implies that for small enough $\varepsilon$, the sum of the two deviation profits above is larger than the sum of the two equilibrium profits, implying that at least one of the deviations is profitable, a contradiction. This concludes that $p_{1}^{j}(s)=p_{2}^{j}(s) \forall j \in\{1,2\}$.

Suppose that $\pi_{1}(s)+\pi_{2}(s)>0$. W.l.o.g. assume $\pi_{1}(s) \geq \pi_{2}(s)$. Then $\pi_{2}(s)<$ $p_{1}^{1}(s)+p_{1}^{2}(s) \leq \pi_{1}(s)+\pi_{2}(s)$ (note that $p_{1}^{j}(s)=p_{2}^{j}(s) \forall j \in\{1,2\}$, and that $p_{1}^{j}(s)$ $<0$ implies that $c_{i}^{j}(s) \neq \emptyset \forall j \in\{1,2\}$ and $\left.i \in[0,1]\right)$. By Lemma 5.1, a deviation $p_{1}^{1}(s)-\varepsilon, p_{1}^{2}(s)-\varepsilon$ by firm 2 for $\varepsilon>0$ guarantees that all consumers choose 2 , which yields a profit of $p_{1}^{1}(s)+p_{1}^{2}(s)-2 \varepsilon$ to firm 2 . This implies that the above deviation is profitable for small enough $\varepsilon$, a contradiction. Then $\pi_{1}(s)+\pi_{2}(s) \leq 0$ and since equilibrium profits have to be nonnegative, $\pi_{1}(s)=\pi_{2}(s)=0$. Suppose $p_{1}^{1}(s)+p_{1}^{2}(s)>0$. By Lemma 5.1, a deviation $p_{1}^{1}(s)-\varepsilon, p_{1}^{2}(s)-\varepsilon$ by firm 2 for $\varepsilon>$ 0 guarantees that all consumers choose 2 , which yields a profit of $p_{1}^{1}(s)+p_{1}^{2}(s)-2 \varepsilon$ to firm 2. But for small enough $\varepsilon$, this profit is positive, which contradicts that $\pi_{2}(s)$ $=0$ and that $s$ is an equilibrium. This concludes that $p_{1}^{1}(s)+p_{1}^{2}(s) \leq 0$. Suppose $p_{1}^{1}(s)+p_{1}^{2}(s)<0$. Then $p_{1}^{j}(s)=p_{2}^{j}(s)<0$ for some $j \in\{1,2\}$. Then $N_{1}^{j}(s)+N_{2}^{j}(s)$ $=1$, since $\emptyset$ is never a best response for any consumer on side $j$ in the subgame after the equilibrium price announcements. But then $\min \left(\pi_{1}(s), \pi_{2}(s)\right)<0$, contradicting that $s$ is a Nash equilibrium. This concludes that $p_{1}^{1}(s)+p_{1}^{2}(s)=0$. If 
$p_{1}^{j}(s)=p_{2}^{j}(s)<0$ for some $j \in\{1,2\}$, then $N_{1}^{j}(s)+N_{2}^{j}(s)=1$. Then nonnegativity of equilibrium profits implies that also $N_{1}^{-j}(s)+N_{2}^{-j}(s)=1$ and that $N_{1}^{1}(s)=N_{1}^{2}(s)$, $N_{2}^{1}(s)=N_{2}^{2}(s)$. If $p_{1}^{1}(s)=p_{2}^{1}(s)=p_{1}^{2}(s)=p_{2}^{2}(s)=0$, then by Lemma 5.1, $N_{1}^{k}(s)+$ $N_{2}^{k}(s)=1 \forall k=1,2$. As shown above, $N_{1}^{j}(s)+N_{2}^{j}(s)>0 \forall j \in\{1,2\}$. Then $p_{1}^{j}(s)$ $=p_{2}^{j}(s) \forall j \in\{1,2\}$ implies $N_{1}^{j}(s)=N_{2}^{j}(s) \forall j \in\{1,2\}$. This implies $\pi_{1}(s)=\pi_{2}(s)$. If $p_{1}^{j}(s)=p_{2}^{j}(s)<0$ for some $j \in\{1,2\}$, then the above implies that $N_{1}^{j}(s)=N_{2}^{j}(s)$ $=1 / 2$. Then $p_{1}^{1}(s)+p_{1}^{2}(s)=0$ and nonnegativity of equilibrium profits together imply that also $N_{1}^{-j}(s)=N_{2}^{-j}(s)=1 / 2$. If $p_{1}^{1}(s)=p_{2}^{1}(s)=p_{1}^{2}(s)=p_{2}^{2}(s)=0$, then $N_{1}^{j}(s)+N_{2}^{j}(s)=1 \forall j \in\{1,2\}$ and the fact that $s$ is a Nash equilibrium imply that $N_{1}^{j}(s)=N_{2}^{j}(s)=1 / 2 \forall j \in\{1,2\}$.

\section{PROOF OF THEOREM 8:}

Lemmas 8.2 and 8.3 establish that there are no other coalition perfect equilibria with one or two active firms than those stated in the claim. All that remains to be shown is that there is no coalition perfect equilibrium with no active firm.

Suppose $N_{1}^{j}(s)+N_{2}^{j}(s)=0 \forall j \in\{1,2\}$. Then $\pi_{1}(s)=\pi_{2}(s)=0$. If $p_{k}^{j}(s)<0$ for some $j, k \in\{1,2\}$, then $N_{1}^{j}(s)+N_{2}^{j}(s)=1$, since $\emptyset$ is a never best response strategy for any consumer on side $j$, a contradiction. Suppose now that $\exists k \in\{1,2\}$ such that $p_{k}^{1}(s), p_{k}^{2}(s) \geq 0$, and $p_{k}^{j}(s)>0$ for some $j \in\{1,2\}$. W.l.o.g. assume $p_{1}^{1}(s)>0$ (and $\left.p_{1}^{2}(s) \geq 0\right)$. By Lemma 5.1, the deviation $\min \left(u^{1}-\varepsilon, p_{1}^{1}(s)-\varepsilon\right), \min \left(u^{2}-\varepsilon, p_{1}^{2}(s)-\right.$ $\varepsilon)$ by firm 2 for $\varepsilon>0$ guarantees that every consumer joins firm 2, and it yields strictly positive profit for small enough $\varepsilon$, a contradiction. If $p_{k}^{j}(s)=0 \forall j=1,2$ and $k \in\{1,2\}$, then $N_{1}^{j}(s)+N_{2}^{j}(s)=1 \forall j \in\{1,2\}$ by Lemma 8.2. This concludes that if $s$ is a coalition perfect equilibrium, then it cannot be that $N_{1}^{j}(s)+N_{2}^{j}(s)=0 \forall j$ $\in\{1,2\}$.

\section{PROOF OF THEOREM 9:}

W.l.o.g. assume that $j=1$ (the other case is perfectly symmetric), so $u^{1}<u^{2}$.

By Theorem 8, if $N_{k}^{1}(s)+N_{k}^{2}(s)>0$ for some $k \in\{1,2\}$, then $p_{k}^{1}(s)=-p_{k}^{2}(s)$ and $p_{k}^{l}(s) \leq u^{l} \forall l=1,2$. Furthermore, $\pi_{1}(s)=\pi_{2}(s)=0$.

Assume $N_{1}^{1}(s)+N_{1}^{2}(s)>0$ and suppose $p_{1}^{1}(s)>u^{1}-u^{2}$. Consider the deviation $p_{1}^{1}(s)-u^{1}-\varepsilon, u^{2}-\varepsilon$ by firm 2 for $\varepsilon>0$. In the subgame following the deviation, is a strictly dominant strategy for every consumer on side 1, therefore it is the only rationalizable strategy. But then 2 is the only rationalizable strategy in the subgame for every consumer on side 2, too. Therefore, after the above deviation, firm 2's profit is $p_{1}^{1}(s)-u^{1}+u^{2}-2 \varepsilon$. Since $p_{1}^{1}(s)>u^{1}-u^{2}$, this profit is strictly positive for small enough $\varepsilon$, contradicting that $s$ is an equilibrium. A perfectly symmetric argument shows that it cannot be that $N_{2}^{1}(s)+N_{2}^{2}(s)>0$ and $p_{2}^{1}(s)>u^{1}-u^{2}$.

\section{PROOF OF THEOREM 10:}

Let $s$ be a coalition perfect equilibrium.

Suppose first that $N_{k}^{j}(s)=0$ for some $j, k \in\{1,2\}$. W.l.o.g. assume $N_{1}^{1}(s)=0$. Then either $N_{1}^{1}(s)=N_{1}^{2}(s)=0$ or $N_{1}^{2}(s)>0$ and $p_{1}^{1}(s)=0$. In either case, $\pi_{1}=0$ and then by the starting assumption $\pi_{2}(s)>0$. Let $\hat{C}_{2}$ be the set of consumers who choose 2 in $s$. Note that $p_{2}^{j}(s)<0$ for some $j \in\{1,2\}$ implies that $C^{j} \subset \hat{C}_{2}$. Consider now deviation $\left(p_{2}^{1}(s)-\varepsilon, p_{2}^{2}(s)-\varepsilon\right)$ for $\varepsilon>0$ by firm 1. By Lemma 5.1, in the subgame 
after this deviation 1 is the unique coalitionally rationalizable strategy for every consumer in $\hat{C}_{2}$. But then for small enough $\varepsilon$ the deviation is profitable, a contradiction. Therefore $N_{k}^{j}(s)>0 \forall j, k \in\{1,2\}$.

If $p_{1}^{j}(s)>p_{2}^{j}(s) \forall j \in\{1,2\}$, then by Lemma $5.1, N_{A}^{1}(s)=N_{A}^{2}(s)=0$ contradicting the above result. Similarly, it cannot be that $p_{1}^{j}(s)<p_{2}^{j}(s) \forall j \in\{1,2\}$.

Consider now $p_{1}^{j}(s)=p_{2}^{j}(s) \forall j \in\{1,2\}$. Let $\hat{C}$ be the set of consumers who join some network in $s$. There exists $k \in\{1,2\}$ such that $\pi_{k}(s) \leq\left(\pi_{1}(s)+\pi_{2}(s)\right) / 2>0$. W.l.o.g. assume $k=1$. Consider deviation $\left(p_{2}^{1}(s)-\varepsilon, p_{2}^{2}(s)-\varepsilon\right)$ by 1 . By Lemma 5.1, every consumer in $\hat{C}$ chooses 1 after the deviation. Therefore, if $\varepsilon$ is small enough, then after this deviation firm 1's profit is larger than $\left(\pi_{1}(s)+\pi_{2}(s)\right) / 2$ (note that $p_{2}^{j}(s)<0$ for some $j \in\{1,2\}$ implies that $\left.C^{j} \subset \hat{C}\right)$, a contradiction.

Finally, notice that if $p_{1}^{j}(s) \leq p_{2}^{j}(s)$ for some $j \in\{1,2\}$, then $N_{2}^{j}(s)>0$ and the assumption that $s$ is a Nash equilibrium imply that $N_{2}^{-j}(s) \geq N_{1}^{-j}(s)$. If $p_{1}^{j}(s)<$ $p_{2}^{j}(s)$ for some $j \in\{1,2\}$, then $N_{2}^{j}(s)>0$ and the assumption that $s$ is a Nash equilibrium imply that $N_{2}^{-j}(s)>N_{1}^{-j}(s)$. Similarly, if $p_{2}^{j}(s) \leq p_{1}^{j}(s)$ (correspondingly $p_{2}^{j}(s)<p_{1}^{j}(s)$ ) for some $j \in\{1,2\}$, then $N_{2}^{-j}(s) \leq N_{1}^{-j}(s)$ (correspondingly $N_{2}^{-j}(s)<$ $\left.N_{1}^{-j}(s)\right)$.

\section{PROOF OF THEOREM 11:}

Let $\Delta=\max _{j \in\{1,2\}} \sup _{i, i^{\prime} \in[0,1]} u_{i}^{j} / u_{i^{\prime}}^{j}$ and let $s$ be a coalition perfect equilibrium. By the starting assumption, $\Delta \leq 4 / 3$.

Assume there is a coalition perfect equilibrium different than 1 or 2 in the statement of the theorem. Then by Lemma 5.1 $\exists j \in\{1,2\}$ such that $p_{1}^{j}(s)<p_{2}^{j}(s), N_{1}^{j}(s)$ $\geq N_{2}^{j}(s)$ and $p_{1}^{-j}(s) \geq p_{2}^{-j}(s), N_{1}^{-j}(s)<N_{2}^{-j}(s)$. For every $j \in\{1,2\}$, let $\inf _{i \in[0,1]} u_{i}^{j}$ $\equiv l^{j}$. Note that $\Delta \leq 4 / 3$ implies that $l^{j}>0$.

If $p_{k}^{j}(s) \leq l^{j} \forall j, k \in\{1,2\}$, then an analogous proof to that of Lemma 8.3 establishes that there is a profitable deviation for at least one firm, contradicting that $s$ is a coalition perfect equilibrium. The same holds if $p_{k}^{j}(s) \geq 0 \forall j, k \in\{1,2\}$. It is straightforward to show that it cannot be that for some $k \in\{1,2\}$, it holds that $p_{k}^{j}(s)$ $>l^{j} \forall j \in\{1,2\}$. Below we consider the remaining possibilities.

Consider first the case that for some $j, k \in\{1,2\}$, it holds that $p_{k}^{j}(s)>l^{j}, p_{k}^{-j}(s)<$ 0 and $0 \leq p_{-k}^{1}(s), p_{-k}^{2}(s)$. Since $\sup _{k} u_{k}^{j} \leq \Delta l^{j} \leq 4 / 3 l^{j}$ and $p_{k}^{j}(s)>l^{j}$, for $N_{k}^{j}(s)>0$ it has to be that $N_{k}^{-j}(s)>3 / 4$ (otherwise no consumer on side $j$ would join $k$ at a price larger than $\left.l^{j}\right)$. Furthermore, $p_{k}^{j}(s)>p_{-k}^{j}(s)$ implies $N_{k}^{j}(s) \leq 1 / 2$, and $\sup _{k} u_{k}^{j} \leq \Delta l^{j}$ $\leq 4 / 3 l^{j}$ implies $p_{k}^{j}(s)<4 / 3 l^{j}$. Therefore $\pi_{k}(s) \leq 2 / 3 l^{j}+3 / 4 p_{k}^{-j}(s)$. This implies $0 \leq$ $2 / 3 l^{j}+3 / 4 p_{k}^{-j}(s)$, which in turn implies $2 / 3 l^{j}+3 / 4 p_{k}^{-j}(s) \leq l^{j} \leq 9 / 8 p_{k}^{-j}(s) \leq l^{j}+p_{k}^{-j}(s)$. Therefore $\pi_{k}(s) \leq l^{j}+p_{k}^{-j}(s)$. But note that $-k$ can get a profit arbitrarily close to $l^{j}+p_{k}^{-j}(s)$ by deviating to price announcements $\left(l^{j}-\varepsilon, p_{k}^{-j}(s)-\varepsilon\right)$ for small enough $\varepsilon>0$ (since by Lemma 5.1, after that price announcement all consumers choose 2). So if $\pi_{-k}(s) \leq \pi_{k}(s)$, then $-k$ has a profitable deviation from $s$. On the other hand note that $k$ can get a profit arbitrarily close to $l^{j}+p_{k}^{-j}(s)$ by deviating to price announcements $\left(p_{-k}^{1}(s)-\varepsilon, p_{-k}^{2}(s)-\varepsilon\right)$ for small enough $\varepsilon>0$. So if $\pi_{-k}(s)$ $>\pi_{k}(s)$ then $k$ has a profitable deviation from $s$. This concludes that $s$ cannot be a coalition perfect equilibrium, a contradiction.

Consider now the case that for some $j, j^{\prime}, k \in\{1,2\}$, it holds that $p_{k}^{j}(s)>l^{j}$ and 0 $>p_{-k}^{j^{\prime}}(s)$. Just like in the previous case, it has to be that $N_{k}^{-j}(s)>3 / 4$ and therefore 
$N_{-k}^{-j}(s)<1 / 4$. Then $\sup _{k} u_{k}^{j} \leq \Delta l^{j} \leq 4 / 3 l^{j}$ implies $p_{-k}^{j}(s)<1 / 3 l^{j}$. Then $0>p_{-k}^{j^{\prime}}(s)$ and $4 / 3 l^{j}>p_{-k}^{-j^{\prime}}(s)$ imply that $\pi_{-k}(s)<1 / 3 l^{j}$. Since $N_{k}^{j}(s) \leq 1 / 2$ and $p_{k}^{j}(s) \leq 4 / 3 l^{j} N_{k}^{-j}(s)$ and $\pi_{k}(s) \geq 0$, it holds that $2 /{ }_{3} l^{j} N_{k}^{-j}(s)+p_{k}^{-j}(s) N_{k}^{-j}(s) \geq 0$, therefore $p_{k}^{-j}(s) \geq-2 / 3 l^{j}$. Therefore $l^{j}+p_{k}^{-j}(s) \geq 1 / 3 l^{j}$. But note that $-k$ can get a profit arbirarily close to $l^{j}+$ $p_{k}^{-j}(s)$ by deviating to price announcement $\left(l^{j}-\varepsilon, p_{k}^{-j}(s)-\varepsilon\right)$ for small enough $\varepsilon>$ 0 . This concludes that $s$ cannot be a coalition perfect equilibrium, a contradiction.

\section{REFERENCES}

Ambrus, Attila. 2006. "Coalitional Rationalizability." Quarterly Journal of Economics, 121(3): 903-29.

Ambrus, Attila. 2003. "Dynamic Coalitional Agreements: Coalitional Rationalizability in Multistage Games." http://www.economics.harvard.edu/faculty/ambrus/files/mstagepapnew.pdf.

-Armstrong, Mark. 2006. "Competition in Two-Sided Markets." RAND Journal of Economics, 37(3): $668-91$.

Baumol, William J., John C. Panzar, and Robert D. Willig. 1982. Contestable Markets and the Theory of Industry Structure. New York: Harcourt Brace.

Bental, Benjamin, and Menahem Spiegel. 1995. "Network Competition, Product Quality, and Market Coverage in the Presence of Network Externalities." Journal of Industrial Economics, 43(2): 197-208.

Bernheim, B. Douglas, Bezalel Peleg, and Michael D. Whinston. 1987. "Coalition-Proof Nash Equilibria: Concepts." Journal of Economic Theory, 42(1): 1-12.

-Caillaud, Bernard, and Bruno Jullien. 2001. "Competing Cybermediaries." European Economic Review, 45(4-6): 797-808.

- Caillaud, Bernard, and Bruno Jullien. 2003. "Chicken \& Egg: Competition among Intermediation Service Providers." RAND Journal of Economics, 34(2): 309-28.

Damiano, Ettore, and Hao Li. 2007. "Price Discrimination and Efficient Matching." Economic Theory, 30(2): 243-63.

Damiano, Ettore, and Hao Li. Forthcoming. "Competing Matchmaking." The Journal of the European Economic Association.

Economides, Nicholas. 1996. "The Economics of Networks." International Journal of Industrial Organization, 14(6): 673-99.

Economides, Nicholas, and Andrzej Skrzypacz. 2003. "Standards Coalitions Formation and Market Structure in Network Industries.” NYU Stern School of Business Working Paper EC-03-08.

Ellison, Glenn, and Drew Fudenberg. 2003. "Knife-Edge or Plateau: When Do Market Models Tip?" Quarterly Journal of Economics, 118(4): 1249-78.

-Ellison, Glenn, Drew Fudenberg, and Markus Mobius. 2004. “Competing Auctions.” Journal of the European Economic Association, 2(1): 30-66.

Evans, David S., Andrei Hagiu, and Richard Schmalensee. 2005. "A Survey of the Economic Role of Software Platforms in Computer-based Industries.” CESifo Economic Studies, 51(2-3): 189-224.

Evans, David S., and Richard Schmalensee. 2005. Paying with Plastic. 2nd. ed. Cambridge: MIT Press.

Farrell, Joseph, and Paul Klemperer. 2006. "Coordination and Lock-In: Competition with Switching Costs and Network Effects." in Handbook of Industrial Organization. Vol. 3., ed. Mark Armstrong and Robert Porter. Amsterdam: Elsevier Science. 1967-2072.

Folland, Sherman, Allen Goodman, and Miron Stano. 2004. The Economics of Health and Health Care. 4th ed. Upper Saddle River, NJ: Prentice Hall.

Gamasutra. 2005. www.gamasutra.com. (accessed September 28, 2005).

Gamespot. 2005. www.gamespot.com. (accessed September 28, 2005).

Innes, Robert, and Richard J. Sexton. 1993. "Customer Coalitions, Monopoly Price Discrimination and Generic Entry Deterrence." European Economic Review, 37(8): 1569-97.

Jullien, Bruno. 2001. "Competing in Network Industries: Divide and Conquer," IDEI Working Paper 112, 2000, revised 2001.

Katz, Michael L., and Carl Shapiro. 1994. "Systems Competition and Network Effects." Journal of Economic Perspectives, 8(2): 93-115.

-Maskin, Eric, and John Riley. 1984. "Monopoly with Incomplete Information.” RAND Journal of Economics, 15(2): 171-96. 
-Mussa, Michael, and Sherwin Rosen. 1978. "Monopoly and Product Quality." Journal of Economic Theory, 18(2): 301-17.

NPD Fun World. 2005. The NPD Group. (accessed September 28, 2005).

Rochet, Jean-Charles, and Jean Tirole. 2002. "Cooperation among Competitors: Some Economics of Payment Card Associations.” RAND Journal of Economics, 33(4): 549-70.

- Rochet, Jean-Charles, and Jean Tirole. 2003. "Platform Competition in Two-Sided Markets." Journal of the European Economic Association, 1(4): 990-1029.

-Rochet, Jean-Charles, and Jean Tirole. 2006. "Two-Sided Markets: A Progress Report." RAND Journal of Economics, 37(3): 645-67.

Salanie, Bernard. 1997. The Economics of Contracts: A Primer. Cambridge: MIT Press.

-Segal, Ilya. 2003. "Coordination and Discrimination in Contracting with Externalities: Divide and Conquer?" Journal of Economic Theory, 113(2): 147-81.

Varian, Hal R. 1989. “Price Discrimination.” In Handbook of Industrial Organization, ed. Richard Schmalensee and Robert D. Willig, 597-654. Amsterdam: Elsevier Science.

- Yanelle, Marie-Odile. 1997. "Banking Competition and Market Efficiency." Review of Economic Studies, 64(2): 215-39. 


\section{This article has been cited by:}

1. Nina Tura, Aino Kuitunen, Lauri Lättilä, Samuli Kortelainen. Increased Value Through Sharing in Multi-Sided Markets 907-924. [Crossref]

2. Masaki Aoyagi. 2018. Bertrand competition under network externalities. Journal of Economic Theory 178, 517-550. [Crossref]

3. Hanna Halaburda, Mikołaj Jan Piskorski, Pınar Yildırım. 2018. Competing by Restricting Choice: The Case of Matching Platforms. Management Science 64:8, 3574-3594. [Crossref]

4. Attila Ambrus, Emilio Calvano, Markus Reisinger. 2016. Either or Both Competition: A "Two-Sided" Theory of Advertising with Overlapping Viewerships. American Economic Journal: Microeconomics 8:3, 189-222. [Abstract] [View PDF article] [PDF with links]

5. Benjamin Edelman, Julian Wright. 2015. Price Coherence and Excessive Intermediation: Table I. The Quarterly Journal of Economics 130:3, 1283-1328. [Crossref]

6. Andrei Hagiu, Hanna Hałaburda. 2014. Information and two-sided platform profits. International Journal of Industrial Organization 34, 25-35. [Crossref]

7. Markus Reisinger. 2014. Two-Part Tariff Competition between Two-Sided Platforms. European Economic Review . [Crossref]

8. Chih-Wei Chang, Yan-Shu Lin, Hiroshi Ohta. 2013. Optimal location in two-sided markets. Economic Modelling 35, 743-750. [Crossref]

9. Hanna Hałaburda, Yaron Yehezkel. 2013. Platform Competition under Asymmetric Information. American Economic Journal: Microeconomics 5:3, 22-68. [Abstract] [View PDF article] [PDF with links]

10. Tanjim Hossain, John Morgan. 2013. When Do Markets Tip? A Cognitive Hierarchy Approach. Marketing Science 32:3, 431-453. [Crossref]

11. Feriha Zingal, Frauke Becker. 2013. Drivers of optimal prices in two-sided markets: the state of the art. Journal für Betriebswirtschaft . [Crossref]

12. Noemí Navarro. 2012. Price and quality decisions under network effects. Journal of Mathematical Economics 48:5, 263-270. [Crossref]

13. Kevin J. Boudreau. 2012. Let a Thousand Flowers Bloom? An Early Look at Large Numbers of Software App Developers and Patterns of Innovation. Organization Science 23:5, 1409-1427. [Crossref]

14. Bruno Jullien. 2011. Competition in Multi-Sided Markets: Divide and Conquer. American Economic Journal: Microeconomics 3:4, 186-219. [Abstract] [View PDF article] [PDF with links]

15. Tanjim Hossain, Dylan Minor, John Morgan. 2011. Competing Matchmakers: An Experimental Analysis. Management Science 57:11, 1913-1925. [Crossref]

16. B. E. Roe, T. E. Wyszynski, J. M. Olimov. 2011. Pigs in Cyberspace: A Natural Experiment Testing Differences between Online and Offline Club-Pig Auctions. American Journal of Agricultural Economics . [Crossref]

17. E. Glen Weyl. 2010. A Price Theory of Multi-Sided Platforms. American Economic Review 100:4, 1642-1672. [Abstract] [View PDF article] [PDF with links]

18. Hendel Igal, Nevo Aviv, Ortalo-Magné François. 2009. The Relative Performance of Real Estate Marketing Platforms: MLS versus FSBOMadison.com. American Economic Review 99:5, 1878-1898. [Abstract] [View PDF article] [PDF with links] 
19. Nina Tura, Aino Kuitunen, Lauri Lättilä, Samuli Kortelainen. Increased Value Through Sharing in Multi-Sided Markets 252-269. [Crossref] 